\title{
Uptake of selected metals in tissues and organs of Clarias gariepinus (sharptooth catfish) from the Vaal River System - Chromium, copper, iron, manganese and zinc
}

\author{
D Crafford ${ }^{1}$ and A Avenant-Oldewage ${ }^{2 *}$ \\ ${ }^{1}$ Department of Zoology, University of Johannesburg, PO Box 524, Auckland Park, Johannesburg, 2006, South Africa \\ Current address: Clinvet International Pty. Ltd., PO Box 11186, Universitas, 9321, South Africa \\ ${ }^{2}$ Department of Zoology, University of Johannesburg, PO Box 524, Auckland Park, Johannesburg 2006, South Africa
}

\begin{abstract}
This paper discusses concentrations of 5 essential trace metals (chromium, copper, iron, manganese and zinc) in water, sediment and various fish (C. gariepinus) tissues. With the exception of high $\mathrm{Zn}$ concentrations in skin, the highest essential element metal concentrations were generally recorded in liver and gill arch tissues, followed by gill filaments and lastly skin and muscle. This general trend is in agreement with trends reported by other workers. Fe concentrations were found to be significantly higher at the Vaal Dam more often than at the Vaal Barrage. In comparison, Mn concentrations were higher at the Vaal River Barrage more often than at the Vaal Dam. No clear trends emerged with regard to differences between localities for the other metals, or between surveys/seasons for all essential trace metals examined. The likely reason for the lack of distinct trends is the amount of variability observed in tissue metal concentrations within localities and seasons in this study. Such variability is also reflected in current literature and accentuates the importance of both abiotic (e.g. physical water quality variables) and biotic (e.g. host physiological status, general biology and life history traits) factors influencing the concentrations and bioavailability of trace metals.
\end{abstract}

Keywords: Heavy metal pollution, bioaccumulation, Clarias gariepinus, Vaal River Barrage, Vaal Dam, chromium, copper, iron, manganese, zinc

\section{Introduction}

\section{Synopsis and scope of study}

There is increased public awareness regarding aquatic pollution, including metal pollution (Strydom et al., 2006). Heavy metals can be defined as 'electropositive elements having a density of greater than five' (Roebuck, 1992). This definition invariably lumps together 40 metals of different properties and degrees of acute and chronic toxicity (Roebuck, 1992). With regard to the periodic table, the transition elements are generally termed 'heavy metals' or simply 'metals' (Sorensen, 1991). While there has been some debate regarding the use of the term 'heavy' (Strydom et al,. 2006), the terms 'heavy metal' and 'metal' are used interchangeably in this paper.

Metal contamination of the environment may emanate from a variety of point sources of pollution, including mining and industrial activity (Kamau, 2002; Strydom et al., 2006; Van Aardt and Hough, 2007; Ayandiran et al., 2009), power generation, irrigation, sewage purification/treatment works (Coetzee et al., 2002), leachates from landfill sites (Moodley et al., 2007), motorboat exhausts (Van Aardt and Erdmann, 2004), leaching from domestic waste products associated with informal settlements (Jackson et al., 2007), other residential areas (Jackson et al., 2009), shooting ranges (Heier et al., 2009) and agricultural activities (Ali and Fishar, 2005). Metal effects on central metabolic pathways may have a major detrimental impact on both human and animal life (Strydom et al.,

\footnotetext{
* To whom all correspondence should be addressed.

용 +2711 559 2449; fax: +2711 559 2286; e-mail: aoldewage@uj.ac.za

Received 31 August 2010; accepted in revised form 1 February 2011.
}

2006; Castro-González and Méndez-Armenta, 2008; Pandey et al., 2008). Metal accumulation has also been employed as an impact assessment tool with reference to fish health (e.g. Deviller et al., 2005; Shah and Altindag, 2005), fish community structure (e.g. Bervoets et al., 2005; Allert et al., 2009) and aquatic ecosystem health (e.g. Birungi et al., 2007; Nesto et al., 2007; Prasath and Khan, 2008; Shinn et al., 2009). Apparent biomagnification of trace metals has also been demonstrated to occur in some cestodes parasitising fish, making these organisms even more sensitive biological indicators of long-term metal pollution exposure (e.g. Woelfl et al., 2008; Retief et al., 2009; Oyoo-Okoth et al., 2010).

This is the second paper in a series of 2 papers reporting on concentrations of 9 metals (strontium, aluminium, chromium, copper, zinc, manganese, iron, lead and nickel), as determined in 5 tissue types, namely, skin, muscle, gill arch, gill filament and liver of the sharptooth catfish (Clarias gariepinus) from the Vaal Dam. The first paper dealt with the non-essential trace metals, aluminium (Al), lead $(\mathrm{Pb})$, nickel $(\mathrm{Ni})$ and strontium (Sr) (Crafford and Avenant-Oldewage, 2010). In the first paper a comprehensive synopsis was provided, including a discussion on various factors that may affect heavy metal accumulation. As a result the same information will not be duplicated here.

Chromium $(\mathrm{Cr})$, copper $(\mathrm{Cu})$, iron $(\mathrm{Fe})$, manganese $(\mathrm{Mn})$, and zinc $(\mathrm{Zn})$ are regarded as essential trace metals (Galvin, 1996), and are reported on in this paper. While the essential trace metals play a vital role in many physiological processes, they can potentially have a toxic effect when present in high concentrations. Determining tissue concentrations of these metals may allow possible effects on the health of fish (and humans that consume them) to be inferred. Catfish are particularly suited to bioaccumulation studies as they are bottom feeders and are readily exposed to metals that accumulate in 
sediment. These bottom-dwelling omnivores also actively feed on a wide variety of prey including small fish (Skelton, 2001). As predators they may thus also accumulate metals from surrounding water or from feeding on other fish (Kidwell et al., 1995).

The data gathered during the study were compared between a polluted (Vaal River Barrage affected by industrial, mining and domestic effluent) and less polluted (Vaal Dam located in the upper catchment) locality. Trace metal concentrations in sediment and water samples (Institute for Water Quality Studies, Department of Water Affairs and Rand Water Board database) were also recorded during each survey.

\section{Chromium}

Chromium $(\mathrm{Cr})$ is involved in glucose metabolism as an insulin co-factor and also increases protein and amino acid uptake by cells (Galvin, 1996). The main sources of $\mathrm{Cr}$ to the environment are effluents from the production of corrosion inhibitors and pigments (Galvin, 1996), electroplating and metal finishing industries, municipal water treatment plants, tanneries, oil drilling operations and cooling towers (Eisler, 1986). High concentrations can cause skin alterations, pulmonary problems and even cancer in humans (Galvin, 1996). Under laboratory conditions chromium is mutagenic, carcinogenic and tetragenic to a wide variety of organisms (Eisler, 1986). Other sublethal effects include: histopathological damage, altered blood parameters such as haematocrit, serum protein levels, and blood glucose levels, decreased enzyme activity and impaired respiratory and locomotory activities (Holdway, 1988). Some degree of toxicity for solutions containing only about $5 \mathrm{mg} / \ell$ has been reported (Trama and Benoit, 1960). Chromium is however generally deemed to be of low importance as a pollutant in the freshwater environment (Lloyd, 1992), since it is less toxic than metals like silver, cadmium, copper and lead (Khangarot and Ray, 1990; Flos et al., 1983).

\section{Copper}

Copper $(\mathrm{Cu})$, as an essential trace element, is involved jointly with cobalt and iron in the production of haemoglobin and erythrocytes (Galvin, 1996). It is also involved in bone and nervous system formation and is contained in some enzymes (e.g. cytochrome and ascorbic acid oxidase) (Galvin, 1996; Sorensen, 1991). High concentrations of copper can alter haematology (James et al., 1998), respiratory and cardiac physiology (Sorensen 1991), and may also lead to retarded growth and inhibition of spawning (Benoit, 1975). Concentrations as low as 5.3 to $31.9 \mathrm{mg} / \ell$ in soft waters may be toxic to larval fish (depending on the $\mathrm{pH}$ and dissolved organic carbon and calcium concentrations) (Welsh et al., 1996).

\section{Iron}

Iron $(\mathrm{Fe})$ is the fourth element in order of abundance on the earth (Galvin, 1996). As such its abundance in the inorganic world stands in stark contrast to its sparing concentration in living cells (Neilands, 1973). Its presence in water originates from rock dissolution and minerals, as well as steel production and other industrial wastewater (Galvin, 1996). As an essential element $\mathrm{Fe}$ is known for its presence in proteins (e.g. haemoglobin), cytochromes and several redox enzymes (Galvin, 1996). In humans ingestion of high amounts of Fe cause irreversible disruptions in several tissues (Galvin, 1996). It can also be toxic to fish like Tilapia sparrmanii, where it alters the routine oxygen consumption (Grobler et al., 1989). Fe is also bio-concentrated in the blood of Tilapia sparrmanii (GroblerVan Heerden et al., 1991).

\section{Manganese}

Manganese (Mn), as essential micronutrient, is a constituent and activator of many enzymes in animals (Martin, 1974). It is widely diffused in nature, and can easily be dissolved by acid solutions (Galvin, 1996). At high concentrations it is toxic to fish, resulting in decreased liver glycogen levels and increased blood glucose levels (Nath and Kumar, 1987).

\section{Zinc}

Zinc (Zn), commonly used as an anti-rust agent, in the galvanizing industry, for paint production and in the textile industry, is also an essential element (Galvin, 1996). In a review on metals in the aquatic environment, Galvin (1996) discusses the function of $\mathrm{Zn}$ as an element essential to life. It is present as $\mathrm{Zn}$-cysteine and $\mathrm{Zn}$-histidine in several amino acids. It is also present in numerous enzymes, such as alcohol dehydrogenase (ethanol metabolism), carboxy peptidase (protein metabolism) and carbonic anhydrase. In the latter zinc plays a role in binding carbon dioxide in teleost cells, combining it with water to form carbonic acid, and releasing carbon dioxide from capillaries at secondary lamellae of the gills (Sorensen, 1991). At excessive concentrations it can cause growth retardation, histopathological alterations, respiratory and cardiac alterations, inhibition of spawning (Sorensen, 1991, Brungs, 1969), damage to gill epithelium (Lloyd, 1960, Skidmore, 1970) resulting in gill tissue hypoxia (Burton et al., 1972), and changes in blood variables (Lewis and Lewis, 1971; Gatlin et al., 1989). Cutthroat trout have been shown to avoid water with a $\mathrm{Zn}$ concentration of $28 \mathrm{mg} / \ell$ (Woodward et al., 1997), before effects on survival and growth were noted.

\section{Aim}

The objectives of this study were to determine to what extent:

- Heavy metal uptake and sequestration occurs in Clarias gariepinus tissues, and, if so, in which tissues (i.e. ranking concentrations in skin, muscle, gill arch, gill filament and liver)

- Metal concentrations differ between localities (Vaal Dam and Vaal River Barrage)

- Metal concentrations differ between surveys and seasons

\section{Materials and methods}

\section{Study sites}

Surveys were conducted bimonthly at 2 localities: the former RAU Island (now UJ island) in the Vaal Dam (S 26 52.249', E $\left.28^{\circ} 10.249^{\prime}\right)$ and the Vaal River Barrage near the Barrage wall (S $26^{\circ} 45.786^{\prime}$, E $\left.27^{\circ} 41.280^{\prime}\right)$. Surveys were conducted during the following months: November 1998, January 1999, March 1999, June 1999, August 1999, October 1999 and February 2000. Water quality in the Vaal River Barrage is poorer than that of the Vaal Dam due to increased levels of urban, industrial, mining and agricultural effluent and runoff (Crafford and Avenant-Oldewage, 2009). 


\section{Water and sediment analyses}

Integrated water samples from 0-5 $\mathrm{m}$ were obtained with the aid of a modified hosepipe. Sediment samples were obtained with the aid of a sediment corer. The Department of Water Affairs Institute for Water Quality Studies (Roodeplaat Dam, Pretoria) performed all water and sediment trace metal analyses. Rand Water Board also made available data on trace meta analyses resulting from their monitoring activities. Data from the following Rand Water Board sampling points were used: C-VD1I (Rand Water Board inlet at the Vaal Dam wall) and C-VRB0T (upstream at the Vaal River Barrage).

\section{Tissue and organ collection}

During each survey 20 C. gariepinus were collected at both localities with the aid of gill nets (stretched mesh sizes 90, 110 and $130 \mathrm{~mm}$.). Fish were transported back to land in a 'live well' (i.e. water-filled chamber on the boat through which water was circulated) and transferred to a holding tank (through which dam or river water was also continuously circulated). Fish were weighed, measured, placed on a polypropylene dissection board and killed by severing the spinal cord behind the head. The following tissues or organs were removed: liver, skin, muscles and gills (filaments attached to arch). For each tissue type an adequate amount (i.e. enough to fill the $25 \mathrm{~m} \ell$ glass bottle in which it was stored) was collected. Samples were kept on ice before being transferred to a deep freezer at the end of each day. The frozen samples were transported to the laboratory.

\section{Laboratory analysis}

In the laboratory samples were allowed to thaw at room temperature. Approximately $5 \mathrm{~g}$ of wet tissue (liver, skin and muscle) were weighed in an Erlenmeyer flask with the aid of a Mettler PK 4800 scale. This corresponded to approximately $1 \mathrm{~g}$ dry weight. Samples were subsequently dried, digested and analysed using a Varian Atomic Absorption Spectrophotometer (SPECTRA AA-10), as described by Crafford and AvenantOldewage (2010).

\section{Results}

\section{Chromium}

\section{Water and sediment}

The low tissue concentrations recorded in the current study were expected, especially when considering the low $\mathrm{Cr}$ concentrations recorded from water (Table 1). In the Vaal Dam Cr was accumulated in the different tissues (Table 2), in order of decreasing concentration as follows: gill filament $\geq$ gill arch $>$ skin $\geq$ liver $\geq$ muscle. In the Vaal River Barrage, the decreasing order of $\mathrm{Cr}$ concentrations in tissues was: gill arch $\geq$ gill filament $\geq$ skin $\geq$ muscle $\geq$ liver. No seasonal trends were evident (Tables 2 and 3).

\section{Copper}

\section{Water and sediment}

Copper sediment and water concentrations (all but one below the respective detection limits) are summarised in Table 4. The same trend was observed from both the Vaal Dam and Vaal

\begin{tabular}{|c|c|c|c|}
\hline \multicolumn{4}{|c|}{$\begin{array}{c}\text { Table } 1 \\
\text { Chromium concentrations in water and sediment of } \\
\text { the Vaal Dam and Vaal River Barrage, obtained during } \\
7 \text { surveys conducted between } 1998 \text { and } 2000\end{array}$} \\
\hline \multirow{2}{*}{$\begin{array}{l}\text { Month of } \\
\text { survey }\end{array}$} & \multirow{2}{*}{$\begin{array}{l}\text { Water or sediment } \\
\text { sample }\end{array}$} & \multicolumn{2}{|c|}{ Locality } \\
\hline & & Vaal Dam & $\begin{array}{c}\text { Vaal River } \\
\text { Barrage }\end{array}$ \\
\hline \multirow{2}{*}{$\begin{array}{l}\text { November } \\
\text { (1998) }\end{array}$} & Water $(\mathrm{mg} / \ell)$ & $<0.025$ & $\mathrm{~N} / \mathrm{A}$ \\
\hline & Sediment (mg/g) & 0.011 & N/A \\
\hline \multirow{2}{*}{$\begin{array}{l}\text { January } \\
(1999)\end{array}$} & Water $(\mathrm{mg} / \mathrm{\ell})$ & $<0.025$ & $<0.025$ \\
\hline & Sediment $(\mathrm{mg} / \mathrm{g})$ & $<0.005$ & $<0.005$ \\
\hline \multirow{2}{*}{$\begin{array}{l}\text { March } \\
(1999)\end{array}$} & Water $(\mathrm{mg} / \ell)$ & $<0.025$ & $<0.025$ \\
\hline & Sediment $(\mathrm{mg} / \mathrm{g})$ & 0.036 & 0.011 \\
\hline \multirow{2}{*}{$\begin{array}{l}\text { June } \\
(1999)\end{array}$} & Water $(\mathrm{mg} / \ell)$ & $<0.025$ & $<0.005$ \\
\hline & Sediment (mg/g) & 0.059 & 0.037 \\
\hline \multirow{2}{*}{$\begin{array}{l}\text { August } \\
(1999)\end{array}$} & Water $(\mathrm{mg} / \mathrm{\ell})$ & $<0.005$ & $<0.005$ \\
\hline & Sediment $(\mathrm{mg} / \mathrm{g})$ & $<0.005$ & 0.026 \\
\hline \multirow{2}{*}{$\begin{array}{l}\text { October } \\
\text { (1999) }\end{array}$} & Water $(\mathrm{mg} / \mathrm{\ell})$ & $<0.005$ & $<0.005$ \\
\hline & Sediment (mg/g) & $<0.005$ & 0.041 \\
\hline \multirow{2}{*}{$\begin{array}{l}\text { February } \\
(2000)\end{array}$} & Water $(\mathrm{mg} / \ell)$ & $<0.005$ & $<0.005$ \\
\hline & Sediment (mg/g) & 0.039 & 0.058 \\
\hline \multicolumn{4}{|c|}{$\begin{array}{l}\text { Analyses by Department of Water Affairs and Forestry } \\
\text { (Institute for Water Quality Studies) }\end{array}$} \\
\hline \multicolumn{4}{|c|}{ Data provided by Rand Water Board } \\
\hline \multicolumn{4}{|c|}{ Highest concentrations are printed in bold } \\
\hline \multicolumn{4}{|c|}{ All concentrations in water are below the detection limit } \\
\hline
\end{tabular}

\begin{tabular}{|c|c|c|c|}
\hline \multicolumn{4}{|c|}{$\begin{array}{c}\text { Table } 4 \\
\text { Copper concentrations in water and sediment of the Vaa } \\
\text { Dam and Vaal River Barrage, obtained during } 7 \text { surveys } \\
\text { conducted between } 1998 \text { and } 2000\end{array}$} \\
\hline \multirow{2}{*}{$\begin{array}{l}\text { Month of } \\
\text { survey }\end{array}$} & \multirow{2}{*}{$\begin{array}{l}\text { Water or sediment } \\
\text { sample }\end{array}$} & \multicolumn{2}{|c|}{ Locality } \\
\hline & & Vaal Dam & $\begin{array}{c}\text { Vaal River } \\
\text { Barrage }\end{array}$ \\
\hline \multirow{2}{*}{$\begin{array}{l}\text { November } \\
(1998)\end{array}$} & 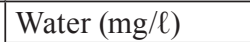 & $<0.050$ & N/A \\
\hline & Sediment (mg/g) & $<0.005$ & N/A \\
\hline \multirow{2}{*}{$\begin{array}{l}\text { January } \\
(1999)\end{array}$} & Water $(\mathrm{mg} / \ell)$ & $<0.050$ & $<0.050$ \\
\hline & Sediment (mg/g) & $<0.005$ & $<0.005$ \\
\hline \multirow{2}{*}{$\begin{array}{l}\text { March } \\
(1999)\end{array}$} & Water $(\mathrm{mg} / \ell)$ & $<0.050$ & $<0.050$ \\
\hline & Sediment $(\mathrm{mg} / \mathrm{g})$ & $<0.005$ & $<0.005$ \\
\hline \multirow{2}{*}{$\begin{array}{l}\text { June } \\
(1999)\end{array}$} & Water $(\mathrm{mg} / \ell)$ & $<0.050$ & $<0.009$ \\
\hline & Sediment $(\mathrm{mg} / \mathrm{g})$ & $<0.005$ & $<0.005$ \\
\hline \multirow{2}{*}{$\begin{array}{l}\text { August } \\
(1999)\end{array}$} & Water $(\mathrm{mg} / \ell)$ & $<0.009$ & $<0.009$ \\
\hline & Sediment $(\mathrm{mg} / \mathrm{g})$ & $<0.005$ & $<0.005$ \\
\hline \multirow{2}{*}{$\begin{array}{l}\text { October } \\
(1999)\end{array}$} & Water $(\mathrm{mg} / \ell)$ & $<0.009$ & $<0.009$ \\
\hline & Sediment $(\mathrm{mg} / \mathrm{g})$ & $<0.005$ & 0.031 \\
\hline \multirow{2}{*}{$\begin{array}{l}\text { February } \\
(2000)\end{array}$} & Water $(\mathrm{mg} / \ell)$ & $<0.009$ & $<0.009$ \\
\hline & Sediment $(\mathrm{mg} / \mathrm{g})$ & $<0.005$ & $<0.005$ \\
\hline \multicolumn{4}{|c|}{$\begin{array}{l}\text { Analyses by Department of Water Affairs and Forestry } \\
\text { (Institute for Water Quality Studies) }\end{array}$} \\
\hline \multicolumn{4}{|c|}{\begin{tabular}{|l|l} 
Data provided by Rand Water Board & \\
\end{tabular}} \\
\hline \multicolumn{4}{|c|}{ Only one reading (in bold) above detection limit recorded } \\
\hline \multicolumn{4}{|c|}{$\mathrm{N} / \mathrm{A}=$ Not available } \\
\hline
\end{tabular}

River Barrage for $\mathrm{Cu}$ concentrations in the different tissues (Table 5): liver $\geq$ gill filament $\geq$ gill arch $\geq$ muscle $\geq$ skin. $\mathrm{Cu}$ concentrations recorded in liver tissue were much higher than that recorded in the other tissues. Concentrations in the remaining tissues were similar. Seasonal trends in differences in metal tissue concentrations between localities were not evident (Tables 5 and 6). 
Table 2

Chromium concentrations $(\mu \mathrm{g} / \mathrm{g})$ in 5 different tissue types of Clarias gariepinus from the Vaal Dam and Vaal River Barrage (shaded blocks). T-test $p$-values indicate whether concentrations recorded in each tissue type differed significantly between localities.

\begin{tabular}{|c|c|c|c|c|c|c|c|c|}
\hline \multirow[t]{2}{*}{ Month } & \multirow[t]{2}{*}{ Locality } & \multirow{2}{*}{$\begin{array}{l}\text { Statistical } \\
\text { Variable }\end{array}$} & \multicolumn{6}{|c|}{ Tissue type } \\
\hline & & & Skin & Liver & Muscle & Gill arch & $\begin{array}{c}\text { Gill } \\
\text { filament }\end{array}$ & $\begin{array}{c}\text { Whole } \\
\text { gill }\end{array}$ \\
\hline November (1998) & Vaal Dam & Mean & 1.07 & 1.01 & 0.54 & - & - & 2.94 \\
\hline & $(\mathrm{n}=20)$ & Std. deviation & 0.70 & 1.01 & 0.72 & - & - & 1.38 \\
\hline \multirow{5}{*}{ January (1999) } & Vaal Dam & Mean & 0.37 & 0.70 & 0.22 & 2.79 & 1.73 & - \\
\hline & $(n=6)$ & Std. deviation & 0.68 & 1.00 & 0.47 & 2.38 & 1.20 & - \\
\hline & & $p$-value & ns & ns & $<0.050$ & ns & ns & - \\
\hline & Barrage & Mean & 0.62 & 1.14 & 1.29 & 2.67 & 1.81 & - \\
\hline & $(n=20)$ & Std. deviation & 0.80 & 1.30 & 0.90 & 1.00 & 1.27 & - \\
\hline \multirow{5}{*}{ March (1999) } & Vaal Dam & Mean & 0.37 & 0.79 & 0.66 & 2.70 & 3.74 & - \\
\hline & $(n=9)$ & Std. deviation & 0.60 & 0.80 & 0.80 & 1.27 & 2.46 & - \\
\hline & & p-value & ns & $<0.050$ & ns & ns & ns & - \\
\hline & Barrage & Mean & 0.24 & 0.06 & 0.77 & 3.43 & 3.39 & - \\
\hline & $(\mathrm{n}=17)$ & Std. deviation & 0.55 & 0.16 & 0.62 & 0.73 & 2.04 & - \\
\hline \multirow{5}{*}{ June (1999) } & Vaal Dam & Mean & 0.47 & 0.68 & 0.24 & 3.54 & 3.75 & - \\
\hline & $(\mathrm{n}=17)$ & Std. deviation & 1.02 & 0.73 & 0.69 & 1.11 & 1.29 & - \\
\hline & & p-value & ns & ns & ns & ns & $<0.050$ & - \\
\hline & Barrage & Mean & 0.63 & 0.83 & 0.00 & 3.38 & 2.00 & - \\
\hline & $(n=6)$ & Std. deviation & 0.71 & 0.58 & 0.00 & 1.24 & 1.81 & - \\
\hline \multirow{5}{*}{ August (1999) } & Vaal Dam & Mean & 0.77 & 0.33 & 0.16 & 2.92 & 2.44 & - \\
\hline & $(\mathrm{n}=18)$ & Std. deviation & 1.30 & 0.53 & 0.21 & 0.75 & 1.18 & - \\
\hline & & p-value & ns & $<0.050$ & ns & ns & ns & - \\
\hline & Barrage & Mean & 0.39 & 0.85 & 0.35 & 2.71 & 1.98 & - \\
\hline & $(n=20)$ & Std. deviation & 0.70 & 0.82 & 0.59 & 1.09 & 0.77 & - \\
\hline \multirow{5}{*}{ October (1999) } & Vaal Dam & Mean & 1.69 & 0.69 & 0.80 & 2.15 & 3.58 & - \\
\hline & $(\mathrm{n}=20)$ & Std. deviation & 1.83 & 0.59 & 0.84 & 1.05 & 5.95 & - \\
\hline & & p-value & ns & $<\mathbf{0 . 0 5 0}$ & ns & ns & ns & - \\
\hline & Barrage & Mean & 1.74 & 0.28 & 0.52 & 2.60 & 2.08 & - \\
\hline & $(\mathrm{n}=20)$ & Std. deviation & 3.79 & 0.39 & 0.52 & 0.92 & 1.33 & - \\
\hline \multirow{5}{*}{ February (2000) } & Vaal Dam & Mean & 0.44 & 0.00 & 0.00 & 0.19 & 0.07 & - \\
\hline & $(n=20)$ & Std. deviation & 0.77 & 0.00 & 0.00 & 0.46 & 0.31 & - \\
\hline & & p-value & $<0.050$ & ns & ns & $<0.010$ & $<0.001$ & - \\
\hline & Barrage & Mean & 0.07 & 0.24 & 0.10 & 1.01 & 1.33 & - \\
\hline & $(n=17)$ & Std. deviation & 0.18 & 0.55 & 0.22 & 0.98 & 1.15 & - \\
\hline \multirow{5}{*}{$\begin{array}{l}\text { Pooled for all } \\
\text { surveys }\end{array}$} & Vaal Dam & Mean & 0.83 & 0.57 & 0.37 & 2.23 & 2.50 & - \\
\hline & $(n=110)$ & Std. deviation & 1.21 & 0.75 & 0.66 & 1.57 & 3.30 & - \\
\hline & & p-value & ns & ns & $<\mathbf{0 . 0 5 0}$ & ns & ns & - \\
\hline & Barrage & Mean & 0.64 & 0.55 & 0.58 & 2.55 & 2.10 & - \\
\hline & $(n=100)$ & Std. deviation & 1.84 & 0.85 & 0.73 & 1.22 & 1.49 & - \\
\hline
\end{tabular}

ns $=$ not significant 


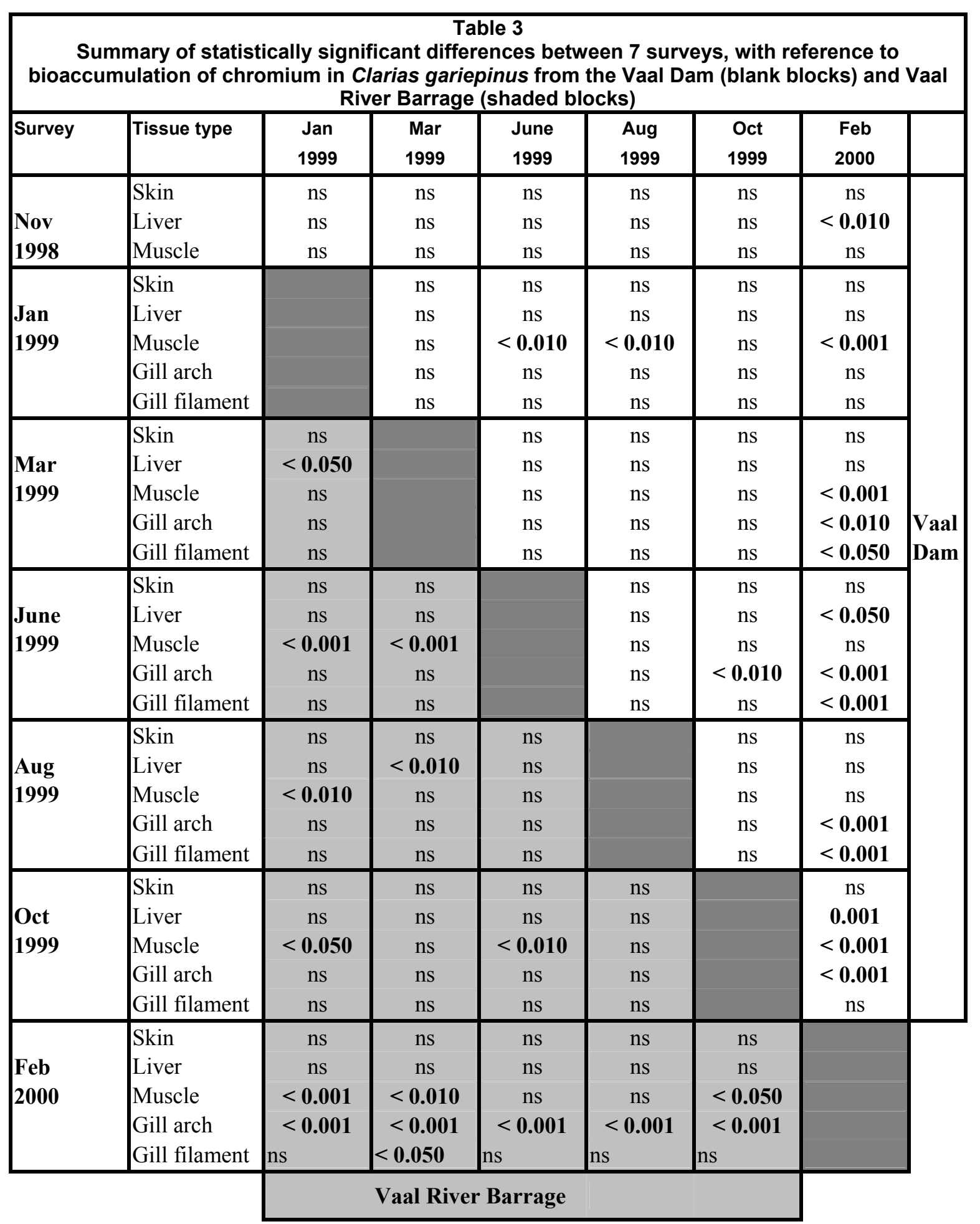

\section{Water and sediment}

Iron concentrations in water and sediment are summarised in Table 7. The ranking of tissues and organs in terms of iron concentration (Table 8) were: Vaal Dam - liver $\geq$ gill filament $\geq$ skin $\geq$ gill arch $\geq$ muscle; Vaal River Barrage - liver $\geq$ gill filament $\geq$ gill $\operatorname{arch} \geq$ skin $\geq$ muscle. Seasonal trends in differences in metal tissue concentrations between localities were not evident (Tables 8 and 9).

\section{Manganese}

\section{Water and sediment}

Manganese concentrations in water from the Vaal Dam were below the limits for detection during all surveys (Table 10). Concentrations recorded in the different tissues (Table 11), listed in decreasing order, were the same for both localities: gill $\operatorname{arch} \geq$ gill filament $\geq$ liver $\geq$ skin $\geq$ muscle. With regards 


\begin{tabular}{|c|c|c|c|c|c|c|c|c|}
\hline $\begin{array}{l}\text { Copper cor } \\
\text { Vaal River }\end{array}$ & $\begin{array}{l}\text { trations } \\
\text { age (shac }\end{array}$ & $\begin{array}{l}\mathrm{g} / \mathrm{g} \text { ) in } 5 \text { diffe } \\
\text { blocks). T-t } \\
\text { ssue type di }\end{array}$ & $\begin{array}{l}\text { nt tissu } \\
\text { t } p \text {-valu } \\
\text { red sig }\end{array}$ & $\begin{array}{l}\text { p } 5 \\
\text { pes of } \\
\text { indicate } \\
\text { santly b }\end{array}$ & $\begin{array}{l}\text { rias ga } \\
\text { hether } \\
\text { eeen loc }\end{array}$ & $\begin{array}{l}\text { inus fror } \\
\text { centratio } \\
\text { ies. }\end{array}$ & $\begin{array}{l}\text { he Vaal } \\
\text { recorde }\end{array}$ & $\begin{array}{l}\text { m and } \\
\text { n each }\end{array}$ \\
\hline Month & Locality & Statistical & & & Tissue t & & & \\
\hline & & variable & Skin & Liver & Muscle & Gill arch & $\begin{array}{l}\text { Gill } \\
\text { filament }\end{array}$ & $\begin{array}{l}\text { Whole } \\
\text { gill }\end{array}$ \\
\hline November (1998) & Vaal Dam & Mean & 2.35 & 26.03 & 3.61 & - & - & 6.59 \\
\hline & $(\mathrm{n}=20)$ & Std. deviation & 0.69 & 12.53 & 1.90 & - & - & 3.92 \\
\hline & Vaal Dam & Mean & 4.36 & 28.02 & 3.72 & 3.47 & 7.37 & - \\
\hline & $(\mathrm{n}=6)$ & Std. deviation & 0.74 & 13.75 & 0.27 & 2.75 & 1.20 & - \\
\hline January (1999) & & p-value & ns & ns & ns & ns & ns & - \\
\hline & Barrage & Mean & 3.95 & 26.40 & 4.45 & 4.86 & 7.12 & - \\
\hline & $(n=20)$ & Std. deviation & 0.80 & 9.66 & 1.61 & 1.44 & 1.89 & - \\
\hline & Vaal Dam & Mean & 2.69 & 31.46 & 2.55 & 6.64 & 7.75 & - \\
\hline & $(n=9)$ & Std. deviation & 0.93 & 11.77 & 1.19 & 2.13 & 2.49 & - \\
\hline March (1999) & & p-value & 0.050 & ns & $<\mathbf{0 . 0 1 0}$ & ns & ns & - \\
\hline & Barrage & Mean & 1.91 & 25.94 & 3.71 & 6.01 & 7.47 & - \\
\hline & $(n=17)$ & Std. deviation & 0.76 & 14.83 & 0.78 & 0.95 & 1.42 & - \\
\hline & Vaal Dam & Mean & 2.78 & 40.91 & 2.40 & 3.61 & 5.23 & - \\
\hline & $(n=17)$ & Std. deviation & 0.78 & 14.68 & 0.83 & 0.58 & 0.76 & - \\
\hline June (1999) & & p-value & ns & ns & ns & ns & ns & - \\
\hline & Barrage & Mean & 2.17 & 36.81 & 1.71 & 3.25 & 4.77 & - \\
\hline & $(n=6)$ & Std. deviation & 0.40 & 9.49 & 0.39 & 0.23 & 0.77 & - \\
\hline & Vaal Dam & Mean & 1.31 & 62.24 & 1.42 & 3.52 & 3.69 & - \\
\hline & $(\mathrm{n}=18)$ & Std. deviation & 0.28 & 50.84 & 0.50 & 0.55 & 1.25 & - \\
\hline August (1999) & & p-value & ns & $<0.050$ & ns & ns & ns & - \\
\hline & Barrage & Mean & 1.33 & 35.83 & 1.71 & 3.71 & 5.17 & - \\
\hline & $(\mathrm{n}=20)$ & Std. deviation & 0.31 & 14.10 & 0.41 & 0.60 & 2.90 & - \\
\hline & Vaal Dam & Mean & 1.85 & 58.04 & 5.35 & 3.91 & 3.87 & - \\
\hline & $(\mathrm{n}=20)$ & Std. deviation & 0.46 & 18.13 & 8.76 & 0.99 & 0.89 & - \\
\hline October (1999) & & p-value & ns & $<0.001$ & ns & $<0.050$ & ns & - \\
\hline & Barrage & Mean & 1.78 & 22.18 & 1.48 & 3.43 & 3.47 & - \\
\hline & $(n=20)$ & Std. deviation & 0.36 & 5.06 & 0.34 & 0.31 & 0.42 & - \\
\hline & Vaal Dam & Mean & 2.63 & 23.78 & 1.11 & 3.63 & 4.06 & - \\
\hline & $(\mathrm{n}=20)$ & Std. deviation & 1.05 & 9.52 & 0.50 & 1.51 & 0.77 & - \\
\hline February (2000) & & p-value & $<0.001$ & $<0.050$ & $<0.001$ & ns & $<0.001$ & - \\
\hline & Barrage & Mean & 1.73 & 39.86 & 3.21 & 4.32 & 5.61 & - \\
\hline & $(\mathrm{n}=17)$ & Std. deviation & 0.51 & 23.47 & 1.63 & 1.53 & 1.29 & - \\
\hline & Vaal Dam & Mean & 2.37 & 40.22 & 2.87 & 4.02 & 4.75 & - \\
\hline Pooled for all & $(\mathrm{n}=110)$ & Std. deviation & 0.98 & 28.17 & 4.06 & 1.52 & 1.81 & - \\
\hline surveys & & p-value & ns & $<0.001$ & ns & $<0.050$ & $<0.010$ & - \\
\hline & Barrage & Mean & 2.19 & 30.28 & 2.80 & 4.35 & 5.66 & - \\
\hline & $(n=100)$ & Std. deviation & 1.06 & 15.30 & 1.57 & 1.37 & 2.24 & - \\
\hline
\end{tabular}


Table 6

Summary of statistically significant differences between 7 surveys, with reference to bioaccumulation of copper in Clarias gariepinus from the Vaal Dam (blank blocks) and Vaal River Barrage (shaded blocks)

\begin{tabular}{|c|c|c|c|c|c|c|c|}
\hline Survey & Tissue type & $\begin{array}{c}\text { Jan } \\
1999\end{array}$ & $\begin{array}{c}\text { Mar } \\
1999\end{array}$ & $\begin{array}{l}\text { June } \\
1999\end{array}$ & $\begin{array}{l}\text { Aug } \\
1999\end{array}$ & $\begin{array}{c}\text { Oct } \\
1999\end{array}$ & $\begin{array}{c}\text { Feb } \\
2000\end{array}$ \\
\hline $\begin{array}{l}\text { Nov } \\
1998\end{array}$ & $\begin{array}{l}\text { Skin } \\
\text { Liver } \\
\text { Muscle }\end{array}$ & $\begin{array}{c}<\mathbf{0 . 0 1 0} \\
\text { ns } \\
\text { ns }\end{array}$ & $\begin{array}{l}\mathrm{ns} \\
\mathrm{ns} \\
\mathrm{ns}\end{array}$ & $\begin{array}{c}\text { ns } \\
<\mathbf{0 . 0 5 0} \\
\text { ns }\end{array}$ & $\begin{array}{c}<\mathbf{0 . 0 0 1} \\
\text { ns } \\
<\mathbf{0 . 0 1 0}\end{array}$ & $\begin{array}{c}\text { ns } \\
<\mathbf{0 . 0 0 1} \\
\text { ns }\end{array}$ & $\begin{array}{l}\text { ns } \\
\text { ns } \\
\text { ns }\end{array}$ \\
\hline $\begin{array}{l}\text { Jan } \\
1999\end{array}$ & $\begin{array}{l}\text { Skin } \\
\text { Liver } \\
\text { Muscle } \\
\text { Gill arch } \\
\text { Gill filament }\end{array}$ & & $\begin{array}{c}<\mathbf{0 . 0 5 0} \\
\text { ns } \\
\text { ns } \\
\text { ns } \\
\text { ns }\end{array}$ & $\begin{array}{c}<\boldsymbol{0 . 0 5 0} \\
\text { ns } \\
<\mathbf{0 . 0 0 1} \\
\text { ns } \\
<\mathbf{0 . 0 5 0}\end{array}$ & $\begin{array}{c}<\mathbf{0 . 0 1 0} \\
\text { ns } \\
<\mathbf{0 . 0 0 1} \\
\text { ns } \\
<\mathbf{0 . 0 0 1}\end{array}$ & $\begin{array}{c}<\boldsymbol{0 . 0 1 0} \\
<0.050 \\
\text { ns } \\
\text { ns } \\
<\mathbf{0 . 0 0 1}\end{array}$ & $\begin{array}{c}<\mathbf{0 . 0 5 0} \\
\text { ns } \\
<\mathbf{0 . 0 0 1} \\
\text { ns } \\
<\mathbf{0 . 0 0 1}\end{array}$ \\
\hline $\begin{array}{l}\text { Mar } \\
1999\end{array}$ & $\begin{array}{l}\text { Skin } \\
\text { Liver } \\
\text { Muscle } \\
\text { Gill arch } \\
\text { Gill filament }\end{array}$ & $\begin{array}{c}<0.001 \\
\text { ns } \\
\text { ns } \\
\text { ns } \\
\text { ns }\end{array}$ & & $\begin{array}{c}\mathrm{ns} \\
\mathrm{ns} \\
<<0.010 \\
<\mathbf{0 . 0 5 0} \\
<\mathbf{0 . 0 0 1}\end{array}$ & $\begin{array}{c}<\mathbf{0 . 0 5 0} \\
\text { ns } \\
<0 \mathbf{0 . 0 0 1} \\
<\mathbf{0 . 0 5 0} \\
<\mathbf{0 . 0 0 1}\end{array}$ & $\begin{array}{c}\text { ns } \\
<\mathbf{0 . 0 1 0} \\
\text { ns } \\
\mathbf{0 . 0 5 0} \\
<\mathbf{0 . 0 0 1}\end{array}$ & $\begin{array}{c}\mathrm{ns} \\
\mathrm{ns} \\
<< \\
<\mathbf{0 . 0 1 0} \\
<\mathbf{0 . 0 5 0} \\
\mathbf{0 . 0 0 1}\end{array}$ \\
\hline $\begin{array}{l}\text { June } \\
1999\end{array}$ & $\begin{array}{l}\text { Skin } \\
\text { Liver } \\
\text { Muscle } \\
\text { Gill arch } \\
\text { Gill filament } \\
\end{array}$ & $\begin{array}{c}<0.001 \\
\text { ns } \\
<0.001 \\
0.001 \\
\text { ns } \\
\end{array}$ & $\begin{array}{c}\text { ns } \\
\text { ns } \\
<0 \mathbf{0 . 0 0 1} \\
<0 \mathbf{0 . 0 0 1} \\
\text { ns } \\
\end{array}$ & & $\begin{array}{c}<\mathbf{0 . 0 0 1} \\
\text { ns } \\
<\mathbf{0 . 0 5 0} \\
\text { ns } \\
<\mathbf{0 . 0 5 0}\end{array}$ & $\begin{array}{c}<\mathbf{0 . 0 1 0} \\
\text { ns } \\
\text { ns } \\
\text { ns } \\
<\mathbf{0 . 0 5 0}\end{array}$ & $\begin{array}{c}\text { ns } \\
<\mathbf{0 . 0 1 0} \\
\text { ns } \\
\text { ns } \\
\text { ns }\end{array}$ \\
\hline $\begin{array}{l}\text { Aug } \\
1999\end{array}$ & $\begin{array}{l}\text { Skin } \\
\text { Liver } \\
\text { Muscle } \\
\text { Gill arch } \\
\text { Gill filament }\end{array}$ & $\begin{array}{c}<\mathbf{0 . 0 0 1} \\
\text { ns } \\
<\mathbf{0 . 0 0 1} \\
<\mathbf{0 . 0 5 0} \\
<\mathbf{0 . 0 5 0}\end{array}$ & $\begin{array}{c}<\mathbf{0 . 0 1 0} \\
\text { ns } \\
<0 \mathbf{0 . 0 0 1} \\
<\mathbf{0 . 0 0 1} \\
<\mathbf{0 . 0 5 0}\end{array}$ & $\begin{array}{c}<0.050 \\
\text { ns } \\
\text { ns } \\
\text { ns } \\
\text { ns }\end{array}$ & & $\begin{array}{c}<0.010 \\
\text { ns } \\
\text { ns } \\
\text { ns } \\
\text { ns }\end{array}$ & $\begin{array}{c}<\mathbf{0 . 0 0 1} \\
\text { ns } \\
\text { ns } \\
\text { ns } \\
\text { ns }\end{array}$ \\
\hline $\begin{array}{l}\text { Oct } \\
1999\end{array}$ & $\begin{array}{l}\text { Skin } \\
\text { Liver } \\
\text { Muscle } \\
\text { Gill arch } \\
\text { Gill filament }\end{array}$ & $\begin{array}{c}<0.001 \\
\text { ns } \\
<0.001 \\
<0.010 \\
<0 \mathbf{0 . 0 0 1}\end{array}$ & $\begin{array}{c}\text { ns } \\
\text { ns } \\
<0 \text { 0.001 } \\
<0 \mathbf{0 . 0 0 1} \\
<\mathbf{0 . 0 0 1}\end{array}$ & $\begin{array}{l}\text { ns } \\
\text { ns } \\
\text { ns } \\
\text { ns } \\
\text { ns }\end{array}$ & $\begin{array}{c}<0.010 \\
<0.010 \\
\text { ns } \\
\text { ns } \\
\text { ns }\end{array}$ & & $\begin{array}{c}<0.010 \\
<0.001 \\
\text { ns } \\
\text { ns } \\
\text { ns }\end{array}$ \\
\hline $\begin{array}{l}\text { Feb } \\
2000\end{array}$ & $\begin{array}{l}\text { Skin } \\
\text { Liver } \\
\text { Muscle } \\
\text { Gill arch } \\
\text { Gill filament }\end{array}$ & 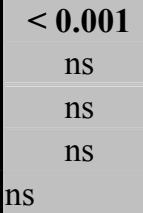 & 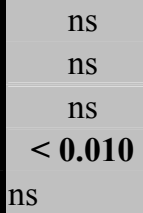 & $\begin{array}{cc} & \mathrm{ns} \\
& \mathrm{ns} \\
< & \mathbf{0 . 0 5 0} \\
& \mathrm{ns} \\
\mathrm{ns} & \end{array}$ & \begin{tabular}{|c|c} 
& $\mathrm{ns}$ \\
& $\mathrm{ns}$ \\
$<$ & $\mathbf{0 . 0 5 0}$ \\
& $\mathrm{ns}$ \\
$\mathrm{ns}$ &
\end{tabular} & $\begin{array}{c}\mathrm{ns} \\
\mathrm{ns} \\
<\mathbf{0 . 0 1 0} \\
\mathrm{ns} \\
<\mathbf{0 . 0 5 0}\end{array}$ & \\
\hline
\end{tabular}

to significant seasonal differences within the localities no clear trends emerged (Tables 11 and 12).

\section{Zinc}

\section{Water and sediment}

Zinc concentrations in water from both localities were below the limits for detection during all surveys (Table 13). Concentrations recorded in the different tissues (Table 14), listed in decreasing order, were: Vaal Dam - liver $\geq$ skin $\geq$ gill filament $\geq$ gill arch $\geq$ muscle; Vaal River Barrage - skin $\geq$ liver $\geq$ gill filament $\geq$ gill arch $\geq$ muscle. No clear seasonal trends emerged (Tables 14 and 15).

\section{Factors that may influence metal availability}

Readings and concentrations of 6 variables that may influence metal availability are given in Fig. 1. Peak flow readings in cubic metres per second were obtained from the Department of Water Affairs database (recorded from the De Vaal

Schoemansdrift gauging weir, Station Number C2H018-A01).

\section{Summary of results}

\section{Water and sediment}

Some of the readings, as indicated in the tables listed earlier, have been obtained from Rand Water Board and others from 


\begin{tabular}{|c|c|c|c|}
\hline \multicolumn{4}{|c|}{$\begin{array}{c}\text { Table } 7 \\
\text { Iron concentrations in water and sediment of the Vaal } \\
\text { Dam and Vaal River Barrage, obtained during } 7 \text { surveys } \\
\text { conducted between } 1998 \text { and } 2000\end{array}$} \\
\hline \multirow{2}{*}{$\begin{array}{l}\text { Month of } \\
\text { survey }\end{array}$} & \multirow{2}{*}{$\begin{array}{l}\text { Water or sediment } \\
\text { sample }\end{array}$} & \multicolumn{2}{|c|}{ Locality } \\
\hline & & Vaal Dam & $\begin{array}{c}\text { Vaal River } \\
\text { Barrage } \\
\end{array}$ \\
\hline \multirow{2}{*}{$\begin{array}{l}\text { November } \\
\text { (1998) }\end{array}$} & Water $(\mathrm{mg} / \ell)$ & $<0.025$ & $\mathrm{~N} / \mathrm{A}$ \\
\hline & Sediment (mg/g) & 8.773 & $\mathrm{~N} / \mathrm{A}$ \\
\hline \multirow{2}{*}{$\begin{array}{l}\text { January } \\
(1999)\end{array}$} & Water $(\mathrm{mg} / \ell)$ & $<0.025$ & 0.121 \\
\hline & Sediment $(\mathrm{mg} / \mathrm{g})$ & 7.183 & 9.715 \\
\hline \multirow{2}{*}{$\begin{array}{l}\text { March } \\
\text { (1999) }\end{array}$} & Water $(\mathrm{mg} / \ell)$ & 0.161 & $<0.025$ \\
\hline & Sediment $(\mathrm{mg} / \mathrm{g})$ & 18.624 & 15.467 \\
\hline \multirow[t]{2}{*}{ June (1999) } & Water $(\mathrm{mg} / \ell)$ & 0.121 & $<0.005$ \\
\hline & Sediment $(\mathrm{mg} / \mathrm{g})$ & 22.975 & 16.723 \\
\hline \multirow{2}{*}{$\begin{array}{l}\text { August } \\
\text { (1999) }\end{array}$} & Water $(\mathrm{mg} / \ell)$ & 0.104 & $<0.005$ \\
\hline & Sediment $(\mathrm{mg} / \mathrm{g})$ & 10.456 & 14.411 \\
\hline \multirow{2}{*}{$\begin{array}{l}\text { October } \\
\text { (1999) }\end{array}$} & Water $(\mathrm{mg} / \ell)$ & 0.077 & $<0.005$ \\
\hline & Sediment $(\mathrm{mg} / \mathrm{g})$ & 6.282 & 26.551 \\
\hline \multirow{2}{*}{$\begin{array}{l}\text { February } \\
(2000)\end{array}$} & Water $(\mathrm{mg} / \mathrm{\ell})$ & $<0.005$ & $<0.005$ \\
\hline & Sediment (mg/g) & 12.805 & 17.503 \\
\hline \multicolumn{4}{|c|}{ Analyses by Department of Water Affairs and Forestry } \\
\hline \multicolumn{4}{|c|}{ (Institute for Water Quality Studies) } \\
\hline \multicolumn{4}{|c|}{ Data provided by Rand Water Board } \\
\hline \multicolumn{4}{|c|}{ Highest concentrations are printed in bold } \\
\hline \multicolumn{4}{|c|}{$\mathrm{N} / \mathrm{A}=$ Not available } \\
\hline
\end{tabular}

the Department of Water Affairs. As a result 2 detection limits have been recorded for the same metal in many cases. It should be noted that this may give rise to 'false' trends.

Concentrations of the 5 metals under review in sediment and water can be divided into 3 categories. Very low concentrations (mostly below the detection limits) of $\mathrm{Cu}$ were recorded in both sediment and water at both localities (Table 4). In the case of $\mathrm{Cr}$ and $\mathrm{Zn}$, most water concentrations were below detection while low concentrations were recorded from sediment (Tables 1 and 13). For Mn and Fe high concentrations were recorded from sediment, while most concentrations in water were found to be below detection (Tables 7 and 10). The high Mn concentrations recorded from the Vaal River Barrage water samples during the October 1999 and January 1999 surveys, respectively, were possibly the result of effluent or re-suspension from sediment.

In general, metal concentrations were not much higher at any one locality, as is evident from the similar maximum concentrations recorded at both localities (Tables 1, 4, 7, 10 and 13).

\section{Concentrations in fish tissue}

While significant seasonal differences in concentration were recorded for all metals, the same tissues were not consistently implicated, making any generalisations difficult. In terms of significant $(p<0.05)$ differences in metal concentrations in fish tissue recorded from the 2 localities (Table 16), some general trends do emerge with regards to $\mathrm{Fe}$ and $\mathrm{Mn}$ in particular.

Fe concentrations were consistently significantly higher (with the exception of the March 1999 survey) at the Vaal Dam and most notably in liver and gill tissues. In comparison Mn concentrations were more often higher at the Vaal River Barrage, once again most often in liver and gill tissues.

\begin{tabular}{|c|c|c|c|}
\hline \multicolumn{4}{|c|}{$\begin{array}{c}\text { Table } 10 \\
\text { Manganese concentrations in water and sediment } \\
\text { of the Vaal Dam and Vaal River Barrage, obtained during } \\
7 \text { surveys conducted between } 1998 \text { and } 2000\end{array}$} \\
\hline \multirow{2}{*}{$\begin{array}{l}\text { Month of } \\
\text { survey }\end{array}$} & \multirow{2}{*}{$\begin{array}{l}\text { Water or sediment } \\
\text { sample }\end{array}$} & \multicolumn{2}{|c|}{ Locality } \\
\hline & & Vaal Dam & $\begin{array}{c}\text { Vaal River } \\
\text { Barrage }\end{array}$ \\
\hline \multirow{2}{*}{$\begin{array}{l}\text { November } \\
\text { (1998) }\end{array}$} & Water $(\mathrm{mg} / \ell)$ & $<0.150$ & N/A \\
\hline & Sediment $(\mathrm{mg} / \mathrm{g})$ & 0.312 & N/A \\
\hline \multirow{2}{*}{$\begin{array}{l}\text { January } \\
(1999)\end{array}$} & Water $(\mathrm{mg} / \ell)$ & $<0.150$ & $<0.150$ \\
\hline & Sediment $(\mathrm{mg} / \mathrm{g})$ & 0.041 & 0.085 \\
\hline \multirow{2}{*}{$\begin{array}{l}\text { March } \\
(1999)\end{array}$} & Water $(\mathrm{mg} / \ell)$ & $<0.150$ & $<0.150$ \\
\hline & Sediment $(\mathrm{mg} / \mathrm{g})$ & 0.557 & 0.306 \\
\hline \multirow{2}{*}{$\begin{array}{l}\text { June } \\
\text { (1999) }\end{array}$} & Water $(\mathrm{mg} / \ell)$ & $<0.150$ & $<0.001$ \\
\hline & Sediment $(\mathrm{mg} / \mathrm{g})$ & 0.418 & 0.341 \\
\hline \multirow{2}{*}{$\begin{array}{l}\text { August } \\
\text { (1999) }\end{array}$} & Water $(\mathrm{mg} / \ell)$ & $<0.001$ & $<0.001$ \\
\hline & Sediment $(\mathrm{mg} / \mathrm{g})$ & 0.097 & 0.241 \\
\hline \multirow{2}{*}{$\begin{array}{l}\text { October } \\
\text { (1999) }\end{array}$} & Water $(\mathrm{mg} / \ell)$ & $<0.001$ & 0.741 \\
\hline & Sediment $(\mathrm{mg} / \mathrm{g})$ & 0.057 & 0.651 \\
\hline \multirow{2}{*}{$\begin{array}{l}\text { February } \\
(2000)\end{array}$} & Water $(\mathrm{mg} / \ell)$ & $<0.001$ & $<0.001$ \\
\hline & Sediment $(\mathrm{mg} / \mathrm{g})$ & 0.186 & 0.343 \\
\hline \multicolumn{4}{|c|}{ Analyses by Department of Water Affairs and Forestry } \\
\hline \multicolumn{4}{|c|}{ (Institute for Water Quality Studies) } \\
\hline \multicolumn{4}{|c|}{ Data provided by Rand Water Board } \\
\hline \multicolumn{4}{|c|}{ Highest concentrations are printed in bold } \\
\hline \multicolumn{4}{|c|}{ Concentrations in water from Vaal Dam below detection limit } \\
\hline \multicolumn{4}{|c|}{$\mathrm{N} / \mathrm{A}=$ Not available } \\
\hline
\end{tabular}

Ranking tissues on the grounds of metal concentrations also allows identification of some trends. At both the Vaal Dam and Vaal River Barrage gill filament tissue was often ranked second with regards to metal concentrations encountered (Table 17). The highest metal concentrations were most often recorded in gill arch or liver tissue, with liver being ranked first most often. At both localities the lowest metal concentrations (with the exception of $\mathrm{Zn}$ ) were most often recorded in muscle and skin tissue.

\section{Discussion}

The Vaal River Barrage receives domestic and industrial runoff and effluent from the Pretoria-Witwatersrand-Vereniging (PWV) area, through streams like the Rietspruit and the Klip and Suikerbosrand Rivers. In terms of physical variables (e.g. salinity and conductivity) and macro-determinants (phosphates, sulphates, etc.), water quality at the Vaal River Barrage is poorer when compared to the Vaal Dam (Crafford and Avenant-Oldewage, 2009). However, contrary to expectations, metal concentrations in sediment and water recorded at both localities were similar, as is also discussed by Crafford and Avenant-Oldewage (2010) with regards to 4 non-essential metals.

As was also reported by Avenant-Oldewage and Marx (2000) in the Olifants River, a large amount of variation amongst the different organs and tissues was recorded with regard to each metal. Such variability may help explain why significantly higher concentrations of metals were not consistently recorded in tissues from the Vaal River Barrage. In view of sediment and water metal concentrations, the simplest explanation would be that the biologically-available metal concentrations at the 2 localities were similar. This is also the most likely explanation. Bioaccumulation of metals in the field 


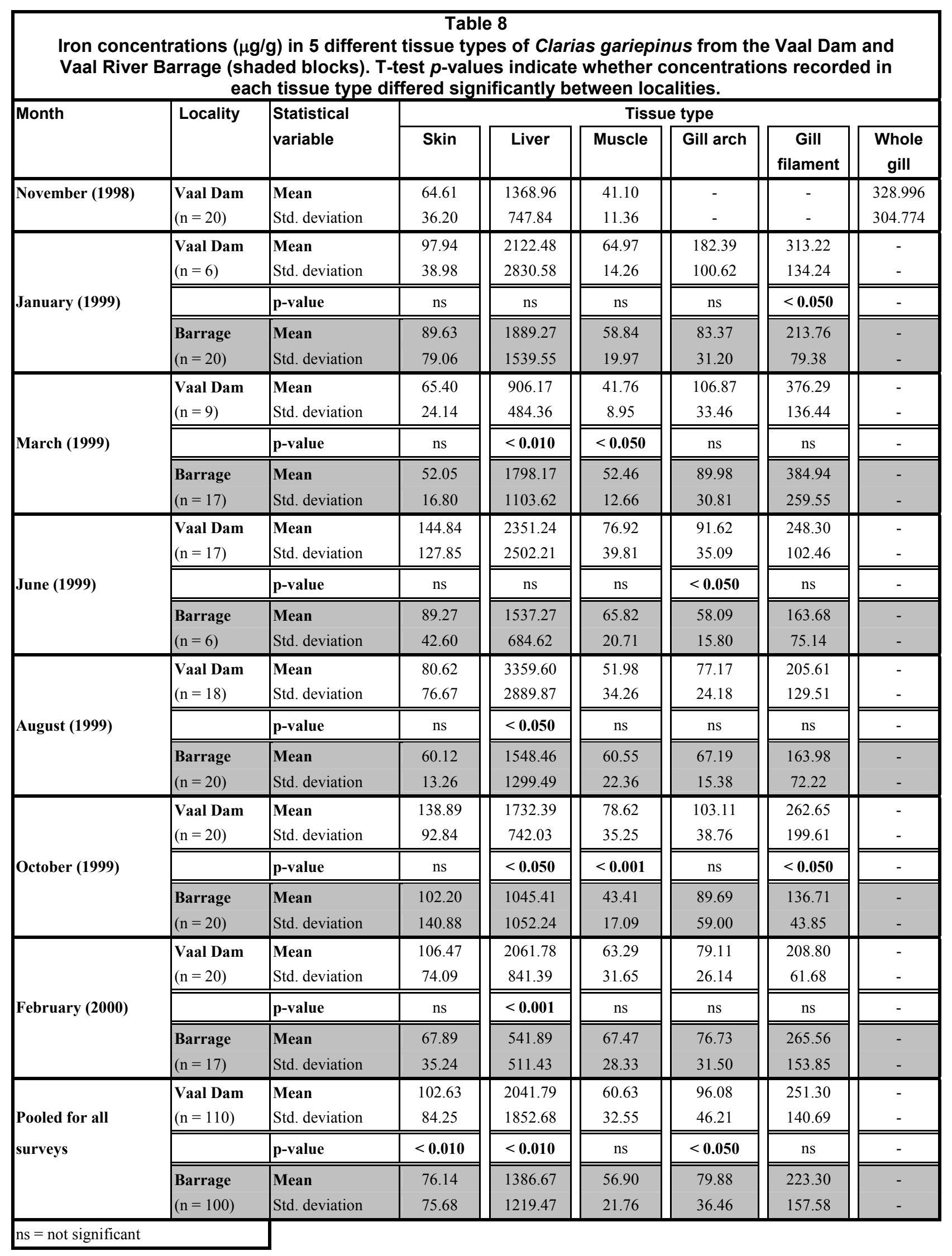




\begin{tabular}{|c|c|c|c|c|c|c|c|c|}
\hline \multicolumn{9}{|c|}{$\begin{array}{c}\text { Table } 9 \\
\text { Summary of statistically significant differences between } 7 \text { surveys, with reference to } \\
\text { bioaccumulation of iron in Clarias gariepinus from the Vaal Dam (blank blocks) and } \\
\text { Vaal River Barrage (shaded blocks) }\end{array}$} \\
\hline Survey & Tissue type & $\begin{array}{c}\text { Jan } \\
1999\end{array}$ & $\begin{array}{c}\text { Mar } \\
1999\end{array}$ & $\begin{array}{l}\text { June } \\
1999\end{array}$ & $\begin{array}{l}\text { Aug } \\
1999\end{array}$ & $\begin{array}{c}\text { Oct } \\
1999\end{array}$ & $\begin{array}{l}\text { Feb } \\
2000\end{array}$ & \\
\hline $\begin{array}{l}\text { Nov } \\
1998\end{array}$ & $\begin{array}{l}\text { Skin } \\
\text { Liver } \\
\text { Muscle }\end{array}$ & $\begin{array}{c}\text { ns } \\
\text { ns } \\
<\mathbf{0 . 0 1 0}\end{array}$ & $\begin{array}{l}\text { ns } \\
\text { ns } \\
\text { ns }\end{array}$ & $\begin{array}{c}\text { ns } \\
\text { ns } \\
<\mathbf{0 . 0 1 0}\end{array}$ & $\begin{array}{l}\text { ns } \\
\text { ns } \\
\text { ns }\end{array}$ & $\begin{array}{c}\mathrm{ns} \\
\mathrm{ns} \\
<\mathbf{0 . 0 5 0}\end{array}$ & $\begin{array}{c}\text { ns } \\
\text { ns } \\
<\mathbf{0 . 0 0 1}\end{array}$ & \\
\hline $\begin{array}{l}\text { Jan } \\
1999\end{array}$ & $\begin{array}{l}\text { Skin } \\
\text { Liver } \\
\text { Muscle } \\
\text { Gill arch } \\
\text { Gill filament }\end{array}$ & & $\begin{array}{l}\text { ns } \\
\text { ns } \\
\text { ns } \\
\text { ns } \\
\text { ns }\end{array}$ & $\begin{array}{l}\text { ns } \\
\text { ns } \\
\text { ns } \\
\text { ns } \\
\text { ns }\end{array}$ & $\begin{array}{l}\text { ns } \\
\text { ns } \\
\text { ns } \\
\text { ns } \\
\text { ns }\end{array}$ & $\begin{array}{l}\text { ns } \\
\text { ns } \\
\text { ns } \\
\text { ns } \\
\text { ns }\end{array}$ & $\begin{array}{l}\mathrm{ns} \\
\mathrm{ns} \\
\mathrm{ns} \\
\mathrm{ns} \\
\mathrm{ns}\end{array}$ & \\
\hline $\begin{array}{l}\text { Mar } \\
1999\end{array}$ & $\begin{array}{l}\text { Skin } \\
\text { Liver } \\
\text { Muscle } \\
\text { Gill arch } \\
\text { Gill filament }\end{array}$ & $\begin{array}{l}\text { ns } \\
\text { ns } \\
\text { ns } \\
\text { ns } \\
\text { ns }\end{array}$ & & $\begin{array}{l}\text { ns } \\
\text { ns } \\
\text { ns } \\
\text { ns } \\
\text { ns }\end{array}$ & $\begin{array}{c}\text { ns } \\
<\mathbf{0 . 0 5 0} \\
\text { ns } \\
\text { ns } \\
\text { ns }\end{array}$ & $\begin{array}{c}\text { ns } \\
<\mathbf{0 . 0 5 0} \\
\text { ns } \\
\text { ns } \\
\text { ns }\end{array}$ & $\begin{array}{c}\text { ns } \\
<\mathbf{0 . 0 1 0} \\
\text { ns } \\
\text { ns } \\
\text { ns }\end{array}$ & $\begin{array}{l}\text { Vaal } \\
\text { Dam }\end{array}$ \\
\hline $\begin{array}{l}\text { June } \\
1999\end{array}$ & $\begin{array}{l}\text { Skin } \\
\text { Liver } \\
\text { Muscle } \\
\text { Gill arch } \\
\text { Gill filament }\end{array}$ & $\begin{array}{l}\text { ns } \\
\text { ns } \\
\text { ns } \\
\text { ns } \\
\text { ns }\end{array}$ & $\begin{array}{l}\text { ns } \\
\text { ns } \\
\text { ns } \\
\text { ns } \\
\text { ns }\end{array}$ & & $\begin{array}{l}\text { ns } \\
\text { ns } \\
\text { ns } \\
\text { ns } \\
\text { ns }\end{array}$ & $\begin{array}{l}\text { ns } \\
\text { ns } \\
\text { ns } \\
\text { ns } \\
\text { ns }\end{array}$ & $\begin{array}{l}\text { ns } \\
\text { ns } \\
\text { ns } \\
\text { ns } \\
\text { ns }\end{array}$ & \\
\hline $\begin{array}{l}\text { Aug } \\
1999\end{array}$ & $\begin{array}{l}\text { Skin } \\
\text { Liver } \\
\text { Muscle } \\
\text { Gill arch } \\
\text { Gill filament }\end{array}$ & $\begin{array}{l}\text { ns } \\
\text { ns } \\
\text { ns } \\
\text { ns } \\
\text { ns }\end{array}$ & $\begin{array}{c}\text { ns } \\
\text { ns } \\
\text { ns } \\
\text { ns } \\
<0.050\end{array}$ & $\begin{array}{l}\text { ns } \\
\text { ns } \\
\text { ns } \\
\text { ns } \\
\text { ns }\end{array}$ & & $\begin{array}{l}\text { ns } \\
\text { ns } \\
\text { ns } \\
\text { ns } \\
\text { ns }\end{array}$ & $\begin{array}{l}\text { ns } \\
\text { ns } \\
\text { ns } \\
\text { ns } \\
\text { ns }\end{array}$ & \\
\hline $\begin{array}{l}\text { Oct } \\
1999\end{array}$ & $\begin{array}{l}\text { Skin } \\
\text { Liver } \\
\text { Muscle } \\
\text { Gill arch } \\
\text { Gill filament }\end{array}$ & $\begin{array}{c}\text { ns } \\
\text { ns } \\
\text { ns } \\
\text { ns } \\
\mathbf{0 . 0 1 0}\end{array}$ & $\begin{array}{c}\text { ns } \\
\text { ns } \\
\text { ns } \\
\text { ns } \\
<0.050\end{array}$ & $\begin{array}{l}\text { ns } \\
\text { ns } \\
\text { ns } \\
\text { ns } \\
\text { ns }\end{array}$ & $\begin{array}{l}\text { ns } \\
\text { ns } \\
\text { ns } \\
\text { ns } \\
\text { ns }\end{array}$ & & $\begin{array}{l}\text { ns } \\
\text { ns } \\
\text { ns } \\
\text { ns } \\
\text { ns }\end{array}$ & \\
\hline $\begin{array}{l}\text { Feb } \\
2000\end{array}$ & $\begin{array}{l}\text { Skin } \\
\text { Liver } \\
\text { Muscle } \\
\text { Gill arch } \\
\text { Gill filament }\end{array}$ & $\begin{array}{c}\text { ns } \\
\text { ns } \\
<\mathbf{0 . 0 5 0} \\
\text { ns } \\
\text { ns }\end{array}$ & $\begin{array}{c}\text { ns } \\
\text { ns } \\
<\mathbf{0 . 0 1 0} \\
\text { ns } \\
\text { ns }\end{array}$ & $\begin{array}{l}\text { ns } \\
\text { ns } \\
\text { ns } \\
\text { ns } \\
\text { ns }\end{array}$ & $\begin{array}{l}\text { ns } \\
\text { ns } \\
\text { ns } \\
\text { ns } \\
\text { ns }\end{array}$ & $\begin{array}{c}\text { ns } \\
\text { ns } \\
<\mathbf{0 . 0 5 0} \\
\text { ns } \\
<\mathbf{0 . 0 5 0}\end{array}$ & & \\
\hline & & & Vaal Rive & 3arrage & & & & \\
\hline
\end{tabular}

is however complex and may be influenced by several factors in addition to levels in food and water (Clements and Rees, 1997; Robinson and Avenant-Oldewage, 1997). A metal bioaccumulation study on catfish, by Avenant-Oldewage and Marx (2000) in the Olifants River, also reported no distinctive trends between localities with variation occurring between different tissues during different seasons at the respective locations. AvenantOldewage and Marx (2000) suggest that this may result from individual variation between fish (e.g. age, gender, health, genetic variability, differential stress during capture, feeding habits, previous disease and time of residence at the sampling site). Gender-specific interactions were demonstrated by Pyle et al. (2005) and Alquezar et al. (2006). To this list of variables affecting accumulation in individual fish one may also add fish size (admittedly correlated with age in most instances), as this influences the rate of physiological processes governing uptake, distribution and elimination of chemical pollutants (Afonso et al., 2007). Pereira et al. (2010b) also stress the relevance of considering distinct season and organs in the assessment of moderately contaminated systems, while Davidson et al. (2009) demonstrated that flushing rates may also be a source of variability in some systems. Otero-Muras et al. (2010) summarise the situation as follows: 'Metal bioaccumulation in fish is influenced by factors specific to the chemical and environmental conditions, the exposure route and the species'. Such variation in metal concentrations in tissues, including differences between fish species and metals examined at the same locality, is indeed not unheard of and has been reported 


\begin{tabular}{|c|c|c|c|c|c|c|c|c|}
\hline \multicolumn{9}{|c|}{$\begin{array}{c}\text { Table } 11 \\
\text { Manganese concentrations }(\mu \mathrm{g} / \mathrm{g}) \text { in } 5 \text { different tissue types of Clarias gariepinus from the Vaal Dam and } \\
\text { Vaal River Barrage (shaded blocks). T-test } p \text {-values indicate whether concentrations recorded in each } \\
\text { tissue type differed significantly between localities. }\end{array}$} \\
\hline \multirow[t]{2}{*}{ Month } & \multirow[t]{2}{*}{ Locality } & \multirow{2}{*}{$\begin{array}{l}\text { Statistical } \\
\text { variable }\end{array}$} & \multicolumn{6}{|c|}{ Tissue type } \\
\hline & & & Skin & Liver & Muscle & Gill arch & $\begin{array}{c}\text { Gill } \\
\text { filament }\end{array}$ & $\begin{array}{c}\text { Whole } \\
\text { gill }\end{array}$ \\
\hline November (1998) & Vaal Dam & Mean & 1.62 & 6.76 & 1.66 & - & - & 25.96 \\
\hline & $(n=20)$ & Std. deviation & 0.62 & 1.37 & 0.47 & - & - & 7.80 \\
\hline \multirow{5}{*}{ January (1999) } & Vaal Dam & Mean & 1.87 & 6.59 & 1.02 & 28.23 & 22.98 & - \\
\hline & $(n=6)$ & Std. deviation & 0.35 & 1.32 & 0.19 & 11.61 & 8.84 & - \\
\hline & & p-value & $\mathrm{ns}$ & ns & 0.001 & $\mathrm{~ns}$ & ns & - \\
\hline & Barrage & Mean & 2.23 & 6.61 & 1.83 & 28.85 & 22.04 & - \\
\hline & $(n=20)$ & Std. deviation & 0.99 & 1.63 & 0.49 & 16.49 & 9.47 & - \\
\hline \multirow{5}{*}{ March (1999) } & Vaal Dam & Mean & 1.25 & 4.47 & 1.09 & 29.29 & 23.07 & - \\
\hline & $(n=9)$ & Std. deviation & 0.39 & 1.78 & 0.14 & 4.16 & 3.97 & - \\
\hline & & p-value & ns & ns & $<0.050$ & $<0.010$ & $<0.010$ & - \\
\hline & Barrage & Mean & 1.48 & 5.36 & 1.35 & 42.79 & 35.59 & - \\
\hline & $(n=17)$ & Std. deviation & 0.42 & 1.54 & 0.31 & 15.16 & 15.38 & - \\
\hline \multirow{5}{*}{ June (1999) } & Vaal Dam & Mean & 2.05 & 5.23 & 2.16 & 31.78 & 22.85 & - \\
\hline & $(\mathrm{n}=17)$ & Std. deviation & 1.83 & 1.55 & 5.96 & 5.04 & 4.79 & - \\
\hline & & p-value & ns & 0.001 & ns & ns & ns & - \\
\hline & Barrage & Mean & 1.61 & 2.76 & 0.67 & 29.59 & 19.46 & - \\
\hline & $(n=6)$ & Std. deviation & 0.80 & 0.49 & 0.29 & 6.94 & 5.17 & - \\
\hline \multirow{5}{*}{ August (1999) } & Vaal Dam & Mean & 1.24 & 3.51 & 0.75 & 26.25 & 22.11 & - \\
\hline & $(\mathrm{n}=18)$ & Std. deviation & 0.93 & 1.54 & 0.21 & 7.42 & 6.54 & - \\
\hline & & p-value & $\mathrm{ns}$ & ns & ns & $<0.010$ & ns & - \\
\hline & Barrage & Mean & 1.28 & 3.51 & 1.11 & 33.76 & 24.81 & - \\
\hline & $(n=20)$ & Std. deviation & 0.31 & 0.97 & 0.82 & 8.20 & 7.40 & - \\
\hline \multirow{5}{*}{ October (1999) } & Vaal Dam & Mean & 1.94 & 4.21 & 1.12 & 32.34 & 23.90 & - \\
\hline & $(n=20)$ & Std. deviation & 1.32 & 1.09 & 0.42 & 10.46 & 6.97 & - \\
\hline & & p-value & ns & $<0.001$ & ns & ns & ns & - \\
\hline & Barrage & Mean & 1.89 & 7.76 & 1.11 & 32.21 & 23.46 & - \\
\hline & $(n=20)$ & Std. deviation & 1.13 & 3.42 & 0.24 & 11.10 & 7.05 & - \\
\hline \multirow{5}{*}{ February (2000) } & Vaal Dam & Mean & 3.50 & 6.55 & 1.54 & 31.76 & 23.27 & - \\
\hline & $(n=20)$ & Std. deviation & 8.02 & 1.80 & 1.05 & 6.99 & 5.99 & - \\
\hline & & p-value & ns & ns & ns & ns & ns & - \\
\hline & Barrage & Mean & 2.27 & 6.97 & 1.58 & 35.55 & 26.29 & - \\
\hline & $(\mathrm{n}=17)$ & Std. deviation & 0.87 & 1.17 & 0.65 & 11.06 & 7.99 & - \\
\hline \multirow{5}{*}{$\begin{array}{l}\text { Pooled for all } \\
\text { surveys }\end{array}$} & Vaal Dam & Mean & 2.01 & 5.29 & 1.39 & 30.31 & 23.06 & - \\
\hline & $(\mathrm{n}=110)$ & Std. deviation & 3.58 & 1.92 & 2.38 & 7.97 & 6.04 & - \\
\hline & & p-value & ns & $<0.010$ & $\mathrm{~ns}$ & $<0.010$ & $<0.050$ & - \\
\hline & Barrage & Mean & 1.82 & 5.84 & 1.35 & 34.06 & 25.75 & - \\
\hline & $(\mathrm{n}=100)$ & Std. deviation & 0.89 & 2.52 & 0.62 & 13.00 & 10.50 & - \\
\hline
\end{tabular}




\begin{tabular}{|c|c|c|c|c|c|c|c|c|}
\hline bio & $\begin{array}{l}\text { nary of statis } \\
\text { mulation of } \mathrm{m}\end{array}$ & $\begin{array}{l}\text { ally sign } \\
\text { Iganese } \\
\text { Vaal }\end{array}$ & $\begin{array}{l}\text { Ta } \\
\text { cant diffe } \\
\text { Clarias } 9 \\
\text { iver Barr }\end{array}$ & $\begin{array}{l}\text { e } 12 \\
\text { nces bet } \\
\text { iepinus f } \\
\text { e (shade }\end{array}$ & $\begin{array}{l}\text { en } 7 \text { sur } \\
\text { n the Va } \\
\text { locks) }\end{array}$ & $\begin{array}{l}\text { /s, with } \\
\text { Jam (bla }\end{array}$ & $\begin{array}{l}\text { rence tc } \\
\text { blocks) }\end{array}$ & \\
\hline Survey & Tissue type & Jan & Mar & June & Aug & Oct & Feb & \\
\hline & & 1999 & 1999 & 1999 & 1999 & 1999 & 2000 & \\
\hline & Skin & ns & ns & ns & ns & $\mathrm{ns}$ & ns & \\
\hline Nov & Liver & ns & $<0.050$ & ns & $<0.001$ & $<0.001$ & ns & \\
\hline 1998 & Muscle & ns & $<0.050$ & ns & $<0.001$ & $<0.010$ & ns & \\
\hline & Skin & & ns & ns & ns & ns & ns & \\
\hline Jan & Liver & & ns & ns & $<0.010$ & ns & ns & \\
\hline 1999 & Muscle & & ns & ns & $<0.001$ & $<0.010$ & ns & \\
\hline & Gill arch & & ns & ns & ns & ns & ns & \\
\hline & Gill filament & & ns & ns & ns & ns & ns & \\
\hline & Skin & ns & & ns & ns & ns & ns & \\
\hline Mar & Liver & $\mathrm{ns}$ & & $\mathrm{ns}$ & ns & ns & ns & \\
\hline 1999 & Muscle & ns & & ns & ns & ns & ns & \\
\hline & Gill arch & ns & & ns & ns & ns & ns & Vaal \\
\hline & Gill filament & ns & & ns & ns & ns & ns & Dam \\
\hline & Skin & ns & ns & & ns & ns & ns & \\
\hline June & Liver & $<0.001$ & $<0.001$ & & ns & ns & ns & \\
\hline 1999 & Muscle & 0.001 & ns & & ns & ns & ns & \\
\hline & Gill arch & ns & ns & & ns & ns & ns & \\
\hline & Gill filament & ns & $<0.050$ & & ns & ns & ns & \\
\hline & Skin & $<0.010$ & ns & ns & & ns & ns & \\
\hline Aug & Liver & $<0.001$ & $<0.010$ & ns & & ns & $<0.001$ & \\
\hline 1999 & Muscle & $<0.010$ & ns & ns & & ns & $<0.050$ & \\
\hline & Gill arch & ns & ns & ns & & ns & ns & \\
\hline & Gill filament & ns & ns & ns & & ns & ns & \\
\hline & Skin & ns & $\mathrm{ns}$ & ns & ns & & ns & \\
\hline Oct & Liver & ns & ns & $<0.001$ & $<0.001$ & & $<0.001$ & \\
\hline 1999 & Muscle & $<0.010$ & ns & ns & ns & & ns & \\
\hline & Gill arch & ns & ns & ns & ns & & ns & \\
\hline & Gill filament & ns & $\mathrm{ns}$ & ns & ns & & ns & \\
\hline & Skin & ns & $<0.050$ & ns & $<0.010$ & ns & & \\
\hline Feb & Liver & ns & $<0.050$ & $<0.001$ & $<0.001$ & ns & & \\
\hline 2000 & Muscle & ns & $\mathrm{ns}$ & $<0.050$ & ns & ns & & \\
\hline & Gill arch & ns & ns & ns & ns & ns & & \\
\hline & Gill filament & ns & ns & ns & ns & ns & & \\
\hline & & & aal Riv & 3arrage & & & & \\
\hline
\end{tabular}

by various other authors (e.g. Mendil et al., 2005; Dural et al., 2007; Mohan et al., 2008; Qiao-Qiao et al., 2007; Schmitt et al., 2007; Arain et al., 2008; Uysal et al., 2008; Lakshmanan et al., 2009; Su et al., 2009; Mendil et al., 2010). Avenant-Oldewage and Marx (2000) also stress possible effects of abiotic variables on metal availability and bioaccumulation. Refer to Robinson and Avenant-Oldewage (1997) for a review on the effect of major inorganic constituents on metal toxicity and accumulation. From the above discussion it can be concluded that factors influencing both metal availability and accumulation are indeed varied. Apart from the influencing factors already mentioned, the effect of interactions between metals on accumulation may be inhibitive (e.g. Kwong and Niyogi, 2009) or synergistic (e.g. Palaniappan and Karthikeyan, 2009). Storage of certain metals may even increase fish's tolerance to toxic metals (Dang and Wang, 2009). Due to the variability observed in the current study and the absence of distinct seasonal trends, detailed discussions on individual seasonal changes for each respective metal, locality and sampling occasion falls outside the scope of this paper. Possible effects of water quality and abiotic variables on metal accumulation in general at the current localities (Vaal Dam and Vaal River Barrage) are discussed by Crafford and Avenant-Oldewage (2010).

With regards to accumulation of the 5 essential metals in question in fish tissue, the general order (ranked in order of decreasing concentrations) was found to be liver / gill arch > gill filament $>$ skin / muscle. This differs slightly from what was recorded for the non-essential metals $(\mathrm{Sr}, \mathrm{Al}, \mathrm{Pb}$ and $\mathrm{Ni})$ 


\begin{tabular}{|c|c|c|c|}
\hline \multicolumn{4}{|c|}{$\begin{array}{c}\text { Table } 13 \\
\text { Zinc concentrations in water and sediment of the Vaal } \\
\text { Dam and Vaal River Barrage, obtained during } 7 \text { surveys } \\
\text { conducted between } 1998 \text { and } 2000\end{array}$} \\
\hline \multirow{2}{*}{$\begin{array}{l}\text { Month of } \\
\text { survey }\end{array}$} & \multirow{2}{*}{$\begin{array}{c}\text { Water or sediment } \\
\text { sample }\end{array}$} & \multicolumn{2}{|c|}{$\begin{array}{l}\text { Locality } \\
\end{array}$} \\
\hline & & Vaal Dam & $\begin{array}{c}\text { Vaal River } \\
\text { Barrage }\end{array}$ \\
\hline \multirow{2}{*}{$\begin{array}{l}\text { November } \\
\text { (1998) }\end{array}$} & Water $(\mathrm{mg} / \ell)$ & $<0.050$ & N/A \\
\hline & Sediment $(\mathrm{mg} / \mathrm{g})$ & 0.231 & N/A \\
\hline \multirow{2}{*}{$\begin{array}{l}\text { January } \\
\text { (1999) }\end{array}$} & Water $(\mathrm{mg} / \ell)$ & $<0.050$ & $<0.050$ \\
\hline & Sediment $(\mathrm{mg} / \mathrm{g})$ & 0.036 & 0.053 \\
\hline \multirow{2}{*}{$\begin{array}{l}\text { March } \\
(1999)\end{array}$} & Water $(\mathrm{mg} / \ell)$ & $<0.050$ & $<0.050$ \\
\hline & Sediment $(\mathrm{mg} / \mathrm{g})$ & 0.057 & 0.099 \\
\hline \multirow[t]{2}{*}{ June (1999) } & Water $(\mathrm{mg} / \ell)$ & $<0.050$ & $<0.008$ \\
\hline & Sediment $(\mathrm{mg} / \mathrm{g})$ & 0.078 & 0.066 \\
\hline
\end{tabular}

\begin{tabular}{|l|l|c|c|}
\hline \multicolumn{4}{|c|}{ Table 13 (continued) } \\
\hline \multirow{2}{*}{$\begin{array}{l}\text { August } \\
(1999)\end{array}$} & Water $(\mathrm{mg} / \ell)$ & $<0.008$ & $<0.008$ \\
\cline { 2 - 4 } & Sediment $(\mathrm{mg} / \mathrm{g})$ & 0.075 & 0.082 \\
\hline $\begin{array}{l}\text { October } \\
(1999)\end{array}$ & Water $(\mathrm{mg} / \ell)$ & $<0.008$ & $<0.008$ \\
\cline { 2 - 4 } & Sediment $(\mathrm{mg} / \mathrm{g})$ & 0.104 & $\mathbf{0 . 2 4 2}$ \\
\hline $\begin{array}{l}\text { February } \\
(2000)\end{array}$ & Water $(\mathrm{mg} / \ell)$ & $<0.008$ & $<0.008$ \\
\cline { 2 - 4 } & Sediment $(\mathrm{mg} / \mathrm{g})$ & 0.197 & 0.136 \\
\hline Analyses by Department of Water Affairs and Forestry \\
\hline (Institute for Water Quality Studies) \\
\hline \multicolumn{4}{|l|}{ Data provided by Rand Water Board } \\
\hline $\begin{array}{l}\text { Highest concentrations are printed in bold } \\
\text { All concentrations in water are below the detection limit }\end{array}$ \\
\hline N/A = Not available \\
\hline
\end{tabular}

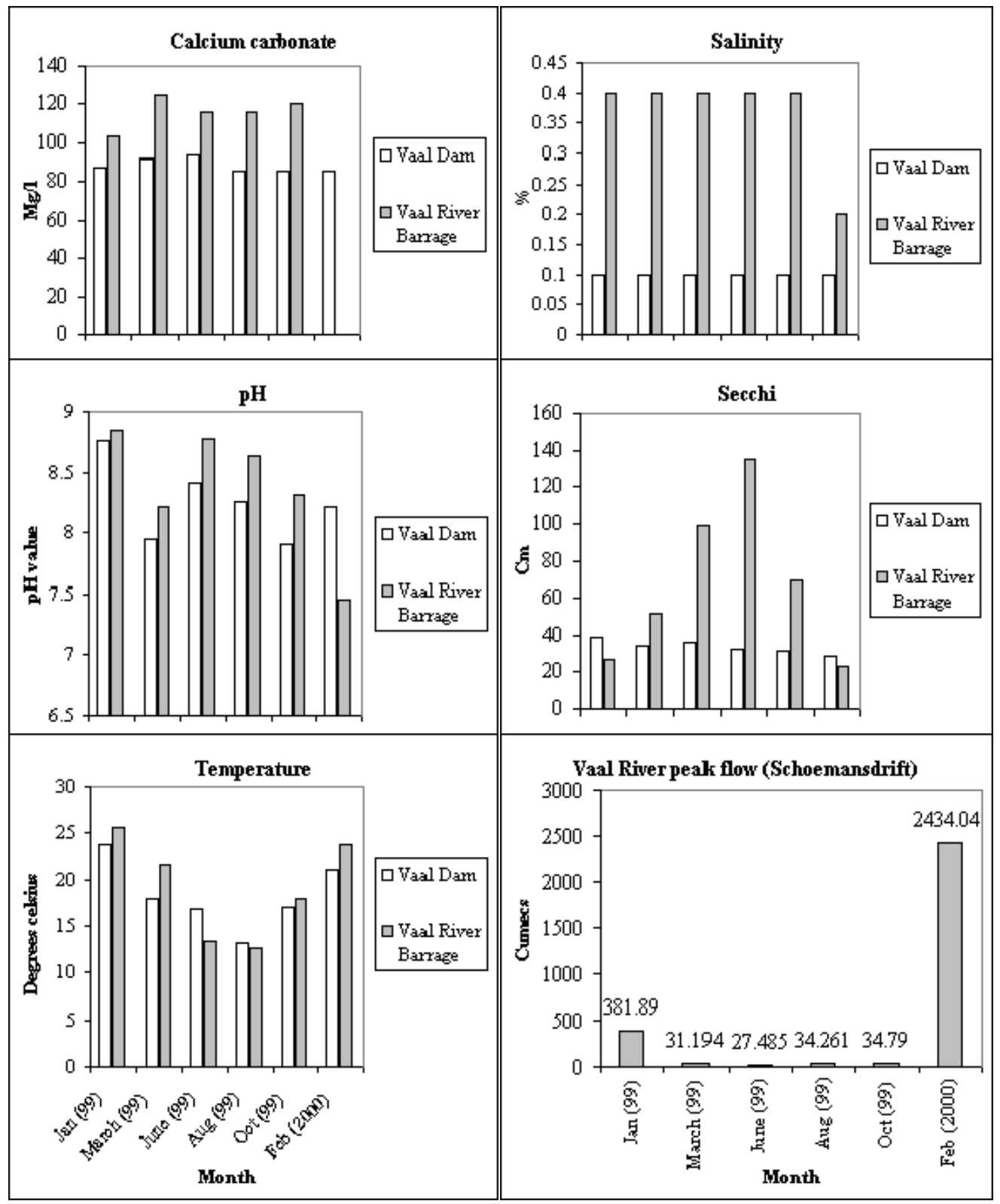

Figure 1

Concentrations and values for variables that affect metal toxicity, availability, water hardness (as calcium carbonate), salinity, $\mathrm{pH}$, suspended solid particles (represented by Secchi disk readings), temperature and peak flow. 


\begin{tabular}{|c|c|c|c|c|c|c|c|c|}
\hline \multicolumn{9}{|c|}{$\begin{array}{c}\text { Table } 14 \\
\text { Zinc concentrations }(\mu \mathrm{g} / \mathrm{g}) \text { in } 5 \text { different tissue types of Clarias gariepinus from the Vaal Dam and } \\
\text { Vaal River Barrage (shaded blocks). T-test } p \text {-values indicate whether concentrations recorded in } \\
\text { each tissue type differed significantly between localities. }\end{array}$} \\
\hline \multirow[t]{2}{*}{ Month } & \multirow[t]{2}{*}{ Locality } & \multirow{2}{*}{$\begin{array}{l}\text { Statistical } \\
\text { variable }\end{array}$} & \multicolumn{6}{|c|}{ Tissue type } \\
\hline & & & Skin & Liver & Muscle & Gill arch & $\begin{array}{c}\text { Gill } \\
\text { filament }\end{array}$ & $\begin{array}{c}\text { Whole } \\
\text { gill }\end{array}$ \\
\hline November (1998) & $\begin{array}{l}\text { Vaal Dam } \\
(\mathrm{n}=20)\end{array}$ & $\begin{array}{l}\text { Mean } \\
\text { Std. deviation }\end{array}$ & $\begin{array}{l}64.41 \\
14.48\end{array}$ & $\begin{array}{l}62.45 \\
26.99\end{array}$ & $\begin{array}{c}24.28 \\
9.56\end{array}$ & $\begin{array}{l}- \\
-\end{array}$ & - & $\begin{array}{l}71.89 \\
27.24\end{array}$ \\
\hline \multirow{3}{*}{ January (1999) } & $\begin{array}{l}\text { Vaal Dam } \\
(\mathrm{n}=6)\end{array}$ & $\begin{array}{l}\text { Mean } \\
\text { Std. deviation }\end{array}$ & $\begin{array}{l}66.25 \\
21.70 \\
\end{array}$ & $\begin{array}{l}95.29 \\
17.57 \\
\end{array}$ & $\begin{array}{c}35.00 \\
9.80 \\
\end{array}$ & $\begin{array}{c}62.62 \\
9.56 \\
\end{array}$ & $\begin{array}{c}69.24 \\
8.40 \\
\end{array}$ & - \\
\hline & & p-value & ns & ns & ns & ns & $\mathrm{ns}$ & - \\
\hline & $\begin{array}{l}\text { Barrage } \\
(\mathrm{n}=20)\end{array}$ & $\begin{array}{l}\text { Mean } \\
\text { Std. deviation }\end{array}$ & $\begin{array}{l}87.23 \\
38.71\end{array}$ & $\begin{array}{l}89.83 \\
15.66\end{array}$ & $\begin{array}{l}37.12 \\
10.09\end{array}$ & $\begin{array}{l}37.12 \\
10.09\end{array}$ & $\begin{array}{l}72.23 \\
19.53\end{array}$ & $\begin{array}{l}- \\
-\end{array}$ \\
\hline \multirow{3}{*}{ March (1999) } & $\begin{array}{l}\text { Vaal Dam } \\
(\mathrm{n}=9)\end{array}$ & $\begin{array}{l}\text { Mean } \\
\text { Std. deviation }\end{array}$ & $\begin{array}{l}66.13 \\
20.17 \\
\end{array}$ & $\begin{array}{l}79.12 \\
13.24 \\
\end{array}$ & $\begin{array}{c}28.04 \\
5.11 \\
\end{array}$ & $\begin{array}{l}65.60 \\
13.94 \\
\end{array}$ & $\begin{array}{l}73.40 \\
16.78 \\
\end{array}$ & - \\
\hline & & p-value & ns & $\mathrm{ns}$ & ns & ns & ns & - \\
\hline & $\begin{array}{l}\text { Barrage } \\
(\mathrm{n}=17)\end{array}$ & $\begin{array}{l}\text { Mean } \\
\text { Std. deviation }\end{array}$ & $\begin{array}{l}73.46 \\
40.16\end{array}$ & $\begin{array}{l}79.65 \\
15.89\end{array}$ & $\begin{array}{l}32.22 \\
10.67\end{array}$ & $\begin{array}{l}68.45 \\
17.26\end{array}$ & $\begin{array}{l}78.83 \\
21.56\end{array}$ & $\begin{array}{l}- \\
-\end{array}$ \\
\hline \multirow{3}{*}{ June (1999) } & $\begin{array}{l}\text { Vaal Dam } \\
(\mathrm{n}=17)\end{array}$ & $\begin{array}{l}\text { Mean } \\
\text { Std. deviation }\end{array}$ & $\begin{array}{l}91.95 \\
49.64 \\
\end{array}$ & $\begin{array}{l}93.30 \\
29.25 \\
\end{array}$ & $\begin{array}{l}41.47 \\
38.63 \\
\end{array}$ & $\begin{array}{l}59.47 \\
12.50 \\
\end{array}$ & $\begin{array}{l}65.60 \\
11.89 \\
\end{array}$ & - \\
\hline & & p-value & $\mathrm{ns}$ & $\mathrm{ns}$ & $\mathrm{ns}$ & $\mathrm{ns}$ & $\mathrm{ns}$ & - \\
\hline & $\begin{array}{l}\text { Barrage } \\
(\mathrm{n}=6)\end{array}$ & $\begin{array}{l}\text { Mean } \\
\text { Std. deviation }\end{array}$ & $\begin{array}{l}72.93 \\
16.61 \\
\end{array}$ & $\begin{array}{l}78.51 \\
20.41 \\
\end{array}$ & $\begin{array}{c}25.77 \\
7.99 \\
\end{array}$ & $\begin{array}{l}61.95 \\
26.24 \\
\end{array}$ & $\begin{array}{l}60.95 \\
18.19 \\
\end{array}$ & - \\
\hline \multirow{3}{*}{ August (1999) } & $\begin{array}{l}\text { Vaal Dam } \\
(\mathrm{n}=18)\end{array}$ & $\begin{array}{l}\text { Mean } \\
\text { Std. deviation }\end{array}$ & $\begin{array}{l}87.33 \\
43.20 \\
\end{array}$ & $\begin{array}{l}79.09 \\
22.04 \\
\end{array}$ & $\begin{array}{c}18.24 \\
4.41 \\
\end{array}$ & $\begin{array}{l}58.07 \\
12.85 \\
\end{array}$ & $\begin{array}{l}60.87 \\
15.06 \\
\end{array}$ & - \\
\hline & & p-value & $\mathrm{ns}$ & $<0.010$ & $\mathrm{~ns}$ & $<0.010$ & $\mathrm{~ns}$ & - \\
\hline & $\begin{array}{l}\text { Barrage } \\
(\mathrm{n}=20)\end{array}$ & $\begin{array}{l}\text { Mean } \\
\text { Std. deviation }\end{array}$ & $\begin{array}{l}71.61 \\
18.32 \\
\end{array}$ & $\begin{array}{l}58.61 \\
11.42 \\
\end{array}$ & $\begin{array}{l}19.93 \\
4.84 \\
\end{array}$ & $\begin{array}{l}47.15 \\
4.89 \\
\end{array}$ & $\begin{array}{l}57.20 \\
12.20 \\
\end{array}$ & - \\
\hline \multirow{3}{*}{ October (1999) } & $\begin{array}{l}\text { Vaal Dam } \\
(\mathrm{n}=20)\end{array}$ & $\begin{array}{l}\text { Mean } \\
\text { Std. deviation }\end{array}$ & $\begin{array}{l}52.68 \\
19.32 \\
\end{array}$ & $\begin{array}{l}70.88 \\
13.54 \\
\end{array}$ & $\begin{array}{c}17.19 \\
3.58 \\
\end{array}$ & $\begin{array}{c}53.18 \\
9.47 \\
\end{array}$ & $\begin{array}{l}57.60 \\
13.88 \\
\end{array}$ & - \\
\hline & & p-value & $\mathrm{ns}$ & $<0.001$ & $\mathrm{~ns}$ & $<\mathbf{0 . 0 5 0}$ & $\mathrm{ns}$ & - \\
\hline & $\begin{array}{l}\text { Barrage } \\
(\mathrm{n}=20)\end{array}$ & $\begin{array}{l}\text { Mean } \\
\text { Std. deviation }\end{array}$ & $\begin{array}{l}64.79 \\
20.12 \\
\end{array}$ & $\begin{array}{l}53.32 \\
10.19 \\
\end{array}$ & $\begin{array}{c}17.93 \\
5.65 \\
\end{array}$ & $\begin{array}{c}47.49 \\
7.37 \\
\end{array}$ & $\begin{array}{l}52.87 \\
9.41 \\
\end{array}$ & - \\
\hline \multirow{3}{*}{ February (2000) } & $\begin{array}{l}\text { Vaal Dam } \\
(\mathrm{n}=20)\end{array}$ & $\begin{array}{l}\text { Mean } \\
\text { Std. deviation }\end{array}$ & $\begin{array}{l}56.26 \\
14.82 \\
\end{array}$ & $\begin{array}{l}73.33 \\
11.62 \\
\end{array}$ & $\begin{array}{c}22.68 \\
4.53 \\
\end{array}$ & $\begin{array}{l}51.31 \\
10.22 \\
\end{array}$ & $\begin{array}{c}57.83 \\
7.03 \\
\end{array}$ & - \\
\hline & & p-value & $<0.050$ & $<0.050$ & $\mathrm{~ns}$ & $\mathrm{~ns}$ & $\mathrm{~ns}$ & - \\
\hline & $\begin{array}{l}\text { Barrage } \\
(\mathrm{n}=17)\end{array}$ & $\begin{array}{l}\text { Mean } \\
\text { Std. deviation }\end{array}$ & $\begin{array}{l}89.00 \\
61.78 \\
\end{array}$ & $\begin{array}{l}94.05 \\
37.06\end{array}$ & $\begin{array}{c}25.94 \\
6.88\end{array}$ & $\begin{array}{l}55.31 \\
19.68\end{array}$ & $\begin{array}{l}63.18 \\
18.80\end{array}$ & - \\
\hline \multirow{4}{*}{$\begin{array}{l}\text { Pooled for all } \\
\text { surveys }\end{array}$} & $\begin{array}{l}\text { Vaal Dam } \\
(\mathrm{n}=110)\end{array}$ & $\begin{array}{l}\text { Mean } \\
\text { Std. deviation }\end{array}$ & $\begin{array}{l}69.04 \\
32.64 \\
\end{array}$ & $\begin{array}{l}76.61 \\
22.80\end{array}$ & $\begin{array}{c}40.40 \\
174.40 \\
\end{array}$ & $\begin{array}{l}56.80 \\
12.05 \\
\end{array}$ & $\begin{array}{l}62.17 \\
13.32 \\
\end{array}$ & - \\
\hline & & p-value & $\mathrm{ns}$ & $\mathrm{ns}$ & $\mathrm{ns}$ & $\mathrm{ns}$ & $\mathrm{ns}$ & - \\
\hline & Barrage & Mean & 76.72 & 74.59 & 26.43 & 57.09 & 64.26 & - \\
\hline & $(\mathrm{n}=100)$ & Std. deviation & 37.50 & 25.22 & 10.56 & 20.44 & 18.82 & - \\
\hline
\end{tabular}




\begin{tabular}{|c|c|c|c|c|c|c|c|c|}
\hline \multicolumn{9}{|c|}{$\begin{array}{c}\text { Table 15 } \\
\text { Summary of statistically significant differences between } 7 \text { surveys, with reference to } \\
\text { bioaccumulation of zinc in Clarias gariepinus from the Vaal Dam (blank blocks) and } \\
\text { Vaal River Barrage (shaded blocks) }\end{array}$} \\
\hline Survey & Tissue type & $\begin{array}{l}\text { Jan } \\
1999\end{array}$ & $\begin{array}{l}\text { Mar } \\
1999\end{array}$ & $\begin{array}{l}\text { June } \\
1999\end{array}$ & $\begin{array}{l}\text { Aug } \\
1999\end{array}$ & $\begin{array}{l}\text { Oct } \\
1999\end{array}$ & $\begin{array}{l}\text { Feb } \\
2000\end{array}$ & \\
\hline $\begin{array}{l}\text { Nov } \\
1998\end{array}$ & $\begin{array}{l}\text { Skin } \\
\text { Liver } \\
\text { Muscle }\end{array}$ & $\begin{array}{l}\text { ns } \\
\text { ns } \\
<\mathbf{0 . 0 1 0}\end{array}$ & $\begin{array}{l}\text { ns } \\
\text { ns } \\
\text { ns }\end{array}$ & $\begin{array}{l}\text { ns } \\
<\mathbf{0 . 0 1 0} \\
\text { ns }\end{array}$ & $\begin{array}{l}\text { ns } \\
\text { ns } \\
\text { ns }\end{array}$ & $\begin{array}{l}\text { ns } \\
\text { ns } \\
\text { ns }\end{array}$ & $\begin{array}{l}\text { ns } \\
\text { ns } \\
\text { ns }\end{array}$ & \\
\hline $\begin{array}{l}\text { Jan } \\
1999\end{array}$ & \begin{tabular}{|l} 
Skin \\
Liver \\
Muscle \\
Gill arch \\
Gill filament
\end{tabular} & & $\begin{array}{l}\text { ns } \\
\text { ns } \\
\text { ns } \\
\text { ns } \\
\text { ns }\end{array}$ & $\begin{array}{l}\text { ns } \\
\text { ns } \\
\text { ns } \\
\text { ns } \\
\text { ns }\end{array}$ & $\begin{array}{l}\text { ns } \\
\text { ns } \\
<\mathbf{0 . 0 0 1} \\
\text { ns } \\
\text { ns }\end{array}$ & $\begin{array}{l}\text { ns } \\
\text { ns } \\
<\mathbf{0 . 0 0 1} \\
\text { ns } \\
\text { ns }\end{array}$ & $\begin{array}{l}\text { ns } \\
\text { ns } \\
<\mathbf{0 . 0 0 1} \\
\text { ns } \\
\text { ns }\end{array}$ & \\
\hline $\begin{array}{l}\text { Mar } \\
1999\end{array}$ & $\begin{array}{l}\text { Skin } \\
\text { Liver } \\
\text { Muscle } \\
\text { Gill arch } \\
\text { Gill filament }\end{array}$ & $\begin{array}{l}\text { ns } \\
\text { ns } \\
\text { ns } \\
\text { ns } \\
\text { ns }\end{array}$ & & $\begin{array}{l}\text { ns } \\
\text { ns } \\
\text { ns } \\
\text { ns }\end{array}$ & $\begin{array}{l}\text { ns } \\
\text { ns } \\
<\mathbf{0 . 0 0 1} \\
\text { ns } \\
\text { ns }\end{array}$ & $\begin{array}{l}\text { ns } \\
\text { ns } \\
<\mathbf{0 . 0 0 1} \\
\text { ns } \\
\text { ns }\end{array}$ & $\begin{array}{l}\text { ns } \\
\text { ns } \\
\text { ns } \\
\text { ns } \\
\text { ns }\end{array}$ & $\begin{array}{l} \\
\text { Vaal } \\
\text { Dam }\end{array}$ \\
\hline $\begin{array}{l}\text { June } \\
1999\end{array}$ & \begin{tabular}{|l} 
Skin \\
Liver \\
Muscle \\
Gill arch \\
Gill filament
\end{tabular} & $\begin{array}{l}\text { ns } \\
\text { ns } \\
\text { ns } \\
\text { ns } \\
\text { ns }\end{array}$ & $\begin{array}{l}\text { ns } \\
\text { ns } \\
\text { ns } \\
\text { ns } \\
\text { ns }\end{array}$ & & $\begin{array}{l}\text { ns } \\
\text { ns } \\
\text { ns } \\
\text { ns } \\
\text { ns }\end{array}$ & $\begin{array}{l}\text { ns } \\
\text { ns } \\
\text { ns } \\
\text { ns } \\
\text { ns }\end{array}$ & $\begin{array}{l}\text { ns } \\
\text { ns } \\
\text { ns } \\
\text { ns } \\
\text { ns }\end{array}$ & \\
\hline $\begin{array}{l}\text { Aug } \\
1999\end{array}$ & $\begin{array}{l}\text { Skin } \\
\text { Liver } \\
\text { Muscle } \\
\text { Gill arch } \\
\text { Gill filament }\end{array}$ & $\begin{array}{l}\text { ns } \\
<\mathbf{0 . 0 0 1} \\
<\mathbf{0 . 0 0 1} \\
\text { ns } \\
\text { ns }\end{array}$ & $\begin{array}{l}\text { ns } \\
0.001 \\
<0.010 \\
<0.010 \\
<0.050\end{array}$ & $\begin{array}{l}\text { ns } \\
\text { ns } \\
\text { ns }\end{array}$ & & $\begin{array}{l}\text { ns } \\
\text { ns } \\
\text { ns } \\
\text { ns } \\
\text { ns }\end{array}$ & $\begin{array}{l}\text { ns } \\
\text { ns } \\
<\mathbf{0 . 0 1 0} \\
\text { ns } \\
\text { ns }\end{array}$ & \\
\hline $\begin{array}{l}\text { Oct } \\
1999\end{array}$ & \begin{tabular}{|l} 
Skin \\
Liver \\
Muscle \\
Gill arch \\
Gill filament
\end{tabular} & $\begin{array}{l}\text { ns } \\
<\mathbf{0 . 0 0 1} \\
<\mathbf{0 . 0 0 1} \\
\text { ns } \\
<\mathbf{0 . 0 5 0}\end{array}$ & $\begin{array}{l}\text { ns } \\
<0.001 \\
0.001 \\
<0.010 \\
0.001\end{array}$ & $\begin{array}{l}\text { ns } \\
\text { ns } \\
\text { ns } \\
\text { ns } \\
\text { ns }\end{array}$ & $\begin{array}{l}\text { ns } \\
\text { ns } \\
\text { ns } \\
\text { ns } \\
\text { ns }\end{array}$ & & $\begin{array}{l}\text { ns } \\
\text { ns } \\
<\mathbf{0 . 0 0 1} \\
\text { ns } \\
\text { ns }\end{array}$ & \\
\hline $\begin{array}{l}\text { Feb } \\
2000\end{array}$ & $\begin{array}{l}\text { Skin } \\
\text { Liver } \\
\text { Muscle } \\
\text { Gill arch } \\
\text { Gill filament }\end{array}$ & $\begin{array}{l}\text { ns } \\
\text { ns } \\
<\mathbf{0 . 0 1 0} \\
\text { ns } \\
\text { ns }\end{array}$ & $\begin{array}{l}\text { ns } \\
\text { ns } \\
\text { ns } \\
\text { ns } \\
\text { ns }\end{array}$ & $\begin{array}{l}\text { ns } \\
\text { ns } \\
\text { ns } \\
\text { ns } \\
\text { ns }\end{array}$ & $\begin{array}{l}\text { ns } \\
<\mathbf{0 . 0 5 0} \\
\text { ns } \\
\text { ns } \\
\text { ns }\end{array}$ & $\begin{array}{l}\text { ns } \\
<0.010 \\
<0.010 \\
\text { ns } \\
\text { ns }\end{array}$ & & \\
\hline
\end{tabular}

from the same locality: gill arch $>$ gill filament $>$ muscle $>$ liver $>$ skin (Crafford and Avenant-Oldewage, 2010). Very high standard deviation values were however recorded, indicating that both of the rankings obtained should be interpreted with caution. The high concentration of $\mathrm{Zn}$ in the skin of catfish from both localities is surprising. Yilmaz et al. (2010) also report highest $\mathrm{Zn}$ concentration from skin in 3 fish species from Turkey. Reynders et al. (2008) found Zn concentrations to be higher in intestine and kidney tissues from 2 fish species in Belgium, while Qiao-Qiao et al. (2007) found highest Zn concentration in gonads. Gbem et al. (2001), however, recorded highest $\mathrm{Cr}, \mathrm{Cu}$ and $\mathrm{Zn}$ concentration in $C$. gariepinus liver and gill tissues. Comparison with available literature from South Africa further supports the general ranking order reflected in the current study (especially with reference to the high concentrations in liver and gill tissues). Avenant-Oldewage and Marx (2000) recorded the greatest $\mathrm{Cr}$ concentration in the gills and the greatest $\mathrm{Cu}$ and $\mathrm{Fe}$ concentrations in the liver. In comparison, Robinson and Avenant-Oldewage (1997) found the highest $\mathrm{Mn}$ concentration in gills, with concentrations of $\mathrm{Cr}$, 


\begin{tabular}{|c|c|c|c|}
\hline \multicolumn{4}{|c|}{$\begin{array}{c}\text { Table } 16 \\
\text { Table summarising instances where statistically significant differences } \\
\text { (T-test) were recorded in Clarias gariepinus tissues between localities } \\
\text { during the respective surveys }\end{array}$} \\
\hline Metal & Survey & ${ }^{1}$ Tissue & ${ }^{2}$ Locality \\
\hline \multirow{7}{*}{ Chromium } & Jan 1999 & ** Muscle & VRB \\
\hline & Mar 1999 & $* *$ Liver & VD \\
\hline & Jun 1999 & ** Gill filament & VD \\
\hline & Aug 1999 & ** Liver & VRB \\
\hline & Oct 1999 & ** Liver & $\mathrm{VD}$ \\
\hline & Feb 2000 & $\begin{array}{l}\text { ** Skin } \\
\text { \# Gill arch; * Gill filament }\end{array}$ & $\begin{array}{l}\text { VD } \\
\text { VRB }\end{array}$ \\
\hline & Pooled & $* *$ Muscle & VRB \\
\hline \multirow{8}{*}{ Copper } & \multirow[t]{2}{*}{ Mar 1999} & $* *$ Skin & VD \\
\hline & & \# Muscle & VRB \\
\hline & Aug 1999 & ** Liver & VD \\
\hline & Oct 1999 & *Liver; ** Gill arch & VD \\
\hline & \multirow[t]{2}{*}{ Feb 2000} & *Skin & VD \\
\hline & & **Liver; *Muscle; * Gill filament & VRB \\
\hline & \multirow[t]{2}{*}{ Pooled } & ** Gill arch; \# Gill filament & VRB \\
\hline & & *Liver & $\mathrm{VD}$ \\
\hline \multirow{7}{*}{ Iron } & Jan 1999 & ** Gill filament & VD \\
\hline & Mar 1999 & \# Liver; ** Muscle & VRB \\
\hline & Jun 1999 & ** Gill arch & $\mathrm{VD}$ \\
\hline & Aug 1999 & ** Liver & VD \\
\hline & Oct 1999 & ** Liver; * Muscle; ** Gill arch & VD \\
\hline & Feb 2000 & *Liver & VD \\
\hline & Pooled & \#Skin; \# Liver; ** Gill arch & VD \\
\hline \multirow{6}{*}{ Manganese } & Jan 1999 & *Muscle & VRB \\
\hline & Mar 1999 & ** Muscle; \# Gill arch; \# Gill filament & VRB \\
\hline & Jun 1999 & *Liver & VD \\
\hline & Aug 1999 & \# Gill arch & VRB \\
\hline & Oct 1999 & *Liver & VRB \\
\hline & Pooled & \#Liver; \# Gill arch; ** Gill filament & VRB \\
\hline \multirow{3}{*}{ Zinc } & Aug 1999 & \# Liver; \# Gill arch & VD \\
\hline & Oct 1999 & *Liver; ** Gill arch & VD \\
\hline & Feb 2000 & ** Skin; ** Liver & VRB \\
\hline \multicolumn{4}{|c|}{$\begin{array}{l}1=\text { Tissues for which significant differences in metal concentration between } \\
\text { localities were recorded. } \\
2=\text { Locality for which the highest metal concentration was recorded. }\end{array}$} \\
\hline \multicolumn{2}{|c|}{$\mathrm{VD}=$ Vaal Dam } & \multicolumn{2}{|c|}{\begin{tabular}{l|l|} 
VRB $=$ Vaal River Barrage
\end{tabular}} \\
\hline \multicolumn{4}{|c|}{$\begin{array}{l}* *=\mathrm{p}<0.050 \\
\#=\mathrm{p}<0.010 \\
*=\mathrm{p} \leq 0.001\end{array}$} \\
\hline
\end{tabular}

$\mathrm{Cu}$ and $\mathrm{Fe}$ being the highest in liver. Retief et al. (2009) also recorded the highest $\mathrm{Cr}, \mathrm{Mn}, \mathrm{Fe}, \mathrm{Cu}$ and $\mathrm{Zn}$ concentrations in liver and the lowest concentrations in muscle. The latter trend was confirmed by Ayandiran et al. (2009) for $\mathrm{Mn}, \mathrm{Zn}$ and $\mathrm{Cu}$. $\mathrm{Zn}$ was however found to occur at higher levels in the gills by Van Aardt and Erdmann (2004), but these authors also recorded the highest $\mathrm{Cu}$ concentrations in liver. The liver is highly active in the uptake and storage of pollutants and non-nutritive molecules (Hopson and Wessels, 1990; Sorensen, 1991; Kimball, 1983), while active and passive exchanges occur between the animal and the aquatic environment through the gills (Eckert et al., 1988; Kargin, 1998). Several other authors also reported highest essential trace metal concentrations in fish liver and/ or gill tissue. Examples include: Yang et al. (2007) for $\mathrm{Cu}$ and
$\mathrm{Zn}$; Y1lmaz et al. (2007) for $\mathrm{Cu}, \mathrm{Fe}$ and $\mathrm{Zn}$; Vinodhini and Narayanan (2008), Al-Kahtani (2009) for $\mathrm{Zn}$ and $\mathrm{Cu}$; Rauf et al. (2009) as well as Su et al. (2009) for Cr and De Boeck et al. (2010) for $\mathrm{Cu}$. Robinson and Avenant-Oldewage (1997) speculated that the large surface area of the gills, and the large volume of water that passes over them, further facilitate metal uptake. The importance of this exposure route is exemplified by the fact that Playle (1998) deems metal-gill modelling a good framework for understanding and predicting metal toxicity to fish. Furthermore Pereira et al. (2010a) believe that gills reflect environmental contamination. With regards to concentrations in liver, Robinson and Avenant-Oldewage (1997) speculate that feeding and biology (e.g. bottom dwelling and feeding), combined with blood supply mechanisms between the liver and 


\begin{tabular}{|c|c|c|c|c|c|c|c|}
\hline \multicolumn{8}{|c|}{$\begin{array}{l}\text { Table } 17 \\
\text { Table depicting the ranking of metal concentrations in } 5 \text { different tissue types, collected from } \\
\text { the Vaal Dam and Vaal River Barrage during } 7 \text { surveys conducted between November } 1998 \text { and } \\
\text { February 2000. To aid in tissue identifications, the different tissue types has been indicated as } \\
\text { follows: Gill arch, Gill filament, Skin, Liver and Muscle. }\end{array}$} \\
\hline & \multicolumn{7}{|c|}{$\begin{array}{ll}\text { Vaal Dam } \\
\end{array}$} \\
\hline Metal & \multicolumn{7}{|c|}{ Ranking of accumulation from highest to lowest concentration } \\
\hline Chromium & Gill filament & $>$ & Gill arch & Skin & $>$ Liver & $>$ & Muscle \\
\hline Manganese & Gill arch & $>$ & Gill filament & Liver & $>$ Skin & $>$ & Muscle \\
\hline Zinc & Liver & $>$ & Skin & Gill filament & $>$ Gill arch & $>$ & Muscle \\
\hline Copper & Liver & $>$ & Gill filament & Gill arch & $>$ Muscle & $>$ & Skin \\
\hline \multirow[t]{2}{*}{ Iron } & Liver & $>$ & Gill filament & Skin & $>$ Gill arch & $>$ & Muscle \\
\hline & \multicolumn{7}{|c|}{$\begin{array}{l}\text { Vaal River Barrage } \\
\end{array}$} \\
\hline Metal & \multicolumn{7}{|c|}{ Ranking of accumulation from highest to lowest concentration } \\
\hline Chromium & Gill arch & $>$ & Gill filament & Skin & $>$ Muscle & & Liver \\
\hline Manganese & Gill arch & $>$ & Gill filament & Liver & $>$ Skin & $>$ & Muscle \\
\hline Zinc & Skin & $>$ & Liver & Gill filament & $>$ Gill arch & $>$ & Muscle \\
\hline Copper & Liver & $>$ & Gill filament & Gill arch & $>$ Muscle & $>$ & Skin \\
\hline Iron & Liver & $>$ & Gill filament & Gill arch & $>$ Skin & $>$ & Muscle \\
\hline
\end{tabular}

intestinal portal system, may help explain high metal concentrations in this organ. Mathews and Fisher (2009) also emphasised the importance of dietary exposure. The fact that metals also accumulate in some aquatic plants (Moodley et al., 2007), may compound the role fish diet may play in metal accumulation. It may thus be interesting to investigate differences in metal accumulation found in catfish (Clarias gariepinus) with that found in a species like grass carp (Ctenopharyngodon idella) from the same locality (e.g. Vaal Dam). Alquezar et al. (2008), examining comparative accumulation from water and food, demonstrated that accumulation pathways differ between metals. As indicated previously, variability in metal concentration levels between different fish species and tissues are well documented. During interpretation of inter-species differences in metal accumulation, care must thus be taken not to simply ascribe a cause-and-effect relationship to any single variable, as such correlations may in fact be shared between a large number of contributing abiotic and biotic factors.

\section{Conclusions}

Essential trace metals were recorded from $C$. gariepinus tissues. The quantification of apparent metal uptake (and subsequent sequestering of metals to various catfish tissues) over a relatively short time period hardly allows any conclusions to be drawn regarding the extent of bioaccumulation. This paper however provides a reference point (i.e. 'baseline data') for the Vaal River system which can be used to quantify possible metal bioaccumulation in catfish tissues during future studies. No clear trends emerged with regards to differences between localities (Vaal Dam and Vaal River Barrage), surveys or seasons. Fe concentrations were however consistently higher (with the exception of the March 1999 survey) at the Vaal Dam. In comparison, Mn concentrations were more often higher at the Vaal River Barrage. Highest essential metal concentrations were generally recorded in liver and gill arches followed by gill filaments. This general trend appears to be in agreement with trends observed by other researchers and reported in the literature. Variability in concentrations from tissues and between seasons / sampling occasions, as is indeed also reported from other studies, accentuate the importance of both abiotic (e.g. physical water quality variables) and also biotic (e.g. host physiological status, general biology and life history traits) factors that may influence the concentrations and bioavailability of trace metals.

\section{Acknowledgements}

The authors would like to thank the former Rand Afrikaans University (now University of Johannesburg) for financial and logistical support, and the National Research Foundation (South Africa) for financial assistance. The opinions expressed herein are those of the authors and the NRF does not accept liability for them. We thank Rand Water for free access to their Water quality data.

\section{References}

AFONSO C, LOURENÇO HM, DIAS A, NUNES ML and CASTRO M (2007) Contaminant metals in black scabbard fish (Aphanopus carbo) caught off Madeira and the Azores. Food Chem. 101 120-125.

ALI MHH and FISHAR MRA (2005) Accumulation of trace metals in some benthic invertebrate and fish species relevant to their concentration in water and sediment of Lake Qarun, Egypt. Egypt. J. Aquat. Res. 31 (1) 289-301.

AL-KAHTANI MA (2009) Accumulation of heavy metals in Tilapia fish (Oreochromis niloticus) from Al-Khadoud Spring, Al-Hassa, Saudi Arabia. Am. J. Appl. Sci. 6 2024-2029.

ALLERT AL, FAIRCHILD JF, SCHMITT CJ, BESSER JM, BRUMBAUGH WG and OLSON SJ (2009) Effects of miningderived metals in riffle-dwelling benthic fishes in Southeast Missouri, USA. Ecotoxicol. Environ. Saf. 72 1642-1651.

ALQUEZAR R, MARKICH SJ and BOOTH DJ (2006) Metal accumulation in the smooth toadfish, Tetractenos glaber, in estuaries around Sydney, Australia. Environ. Pollut. 142 123-131.

ALQUEZAR R, MARKICH SJ and TWINING JR (2008) Comparative accumulation of ${ }^{109} \mathrm{Cd}$ and ${ }^{75} \mathrm{Se}$ from water and food by an estuarine fish (Tetractenos glaber). J. Environ. Radioactiv. 99 167-180.

ARAIN MB, KAZI TG, JAMALI MK, JALBANI N, AFRIDI HI and SHAH A (2008) Total dissolved and bioavailable elements in water and sediments samples and their accumulation in Oreochromis 
mossambicus of polluted Manchar Lake. Chemosphere 70 1845-1856.

AVENANT-OLDEWAGE A and MARX HM (2000) Bioaccumulation of chromium, copper and iron in the organs and tissues of Clarias gariepinus in the Olifants River, Kruger National Park. Water SA 26 (4) 569-582.

AYANDIRAN TA, FAWOLE OO, ADEWOYE SO and OGUNDIRAN MA (2009) Bioconcentration of metals in the body muscle and gut of Clarias gariepinus exposed to sublethal concentrations of soap and detergent effluent. J. Cell Anim. Biol. 3 (8) 113-118.

BENOIT DA (1975) Chronic effects of copper on survival, growth, and reproduction of the bluegill (Lepomis macrochirus). Trans. Am. Fish. Soc. 2: $353-358$

BERVOETS L, KNAEPKENS G, EENS M and BLUST R (2005) Fish community responses to metal pollution. Environ. Pollut. 138 338-349.

BIRUNGI Z, MASOLA B, ZARANYIKA MF, NAIGAGA I and MARSHALL B (2007) Active biomonitoring of trace heavy metals using fish (Oreochromis niloticus) as bioindicator species. The case of Nakivubo wetland along Lake Victoria. Phys. Chem. Earth 32 1350-1358.

BRUNGS WA (1969) Chronic toxicity of zinc to the fathead minnow, Pimephales promelas Rafinesque. Trans. Am. Fish. Soc. 2 272-279.

BURTON DT, JONES AH and CAIRNS J (1972) Acute zinc toxicity to rainbow trout (Salmo gairdneri): confirmation of the hypothesis that death is related to tissue hypoxia. J. Fish. Res. Board Can. 29 (10) 1463-1466.

CASTRO-GONZÁLEZ MI and MÉNDEZ-ARMENTA M (2008) Heavy metals: Implications associated to fish consumption. Ecotoxicol. Environ. Saf. 26 263-271.

CLEMENTS, WH and REES DE (1997) Effects of heavy metals on prey abundance, feeding habits, and metal uptake of brown trout in the Arkansas River, Colorado. Trans. Am. Fish. Soc. 126 774-785.

COETZEE L, DU PREEZ HH and VAN VUREN JHJ (2002) Metal concentrations in Clarias gariepinus and Labeo umbratus from the Olifants and Klein Olifants River, Mpumalanga, South Africa: Zinc, copper, manganese, lead, chromium, nickel, aluminium and iron. Water SA 28 (4) 433-448.

CRAFFORD D and AVENANT-OLDEWAGE A (2009) Application of a fish health assessment index and associated parasite index to Clarias gariepinus (Teleostei: Clariidae) in the Vaal river system, South Africa. Afr. J. Aquat. Sci. 34 (3) 261-272.

CRAFFORD D and AVENANT-OLDEWAGE A (2010) Bioaccumulation of non-essential trace metals in tissues and organs of Clarias gariepinus (sharptooth catfish) from the Vaal River system strontium, aluminium, lead and nickel. Water SA 36 (5) 621-640.

DANG F and WANG W-X (2009) Assessment of tissue-specific accumulation and effects of cadmium in a marine fish fed contaminated commercially produced diet. Aquat. Toxicol. 95 248-255.

DAVIDSON J, GOOD C, WELSH C, BRAZIL B and SUMMERFELT S (2009) Heavy metal and waste metabolite accumulation and their potential effect on rainbow trout performance in a replicated water reuse system operated at low or high system flushing rates. Aquacult. Eng. 41 136-145.

DE BOECK G, EYCKMANS M, LARDON I, ROBBAERS R, SINHA AK and BLUST R (2010) Metal accumulation and metallothionein induction in the spotted dogfish Scyliorhinus canicula. Comp. Biochem. Physiol. A 155 503-508.

DEVILLER G, PALLUEL O, ALIAUME C, ASANTHI H, SANCHEZ W, MA FRANCO NAVA, BLANCHETON J-P and CASELLAS $C$ (2005) Impact assessment of various rearing systems on fish health using multibiomarker response and metal accumulation. Ecotoxicol. Environ. Saf. 61 89-97.

DURAL M, GÖKSU MZL and ÖZAK AA (2007) Investigation of heavy metal levels in economically important fish species captured from the Tuzla lagoon. Food Chem. 102 415-421.

ECKERT R, RANDALL D and AUGUSTINE G (1988) Animal Physiology; Mechanisms and Adaptations. W.H. Freeman and Company, New York.

EISLER R (1986) Chromium hazards to fish, wildlife, and invertebrates: a synoptic review. Contaminant Hazard Reviews Report
No. 6. Biological report 85 (1.6). Fish and Wildlife Service, U.S. Department of the Interior.

FLOS R, RIVA MC and BALASCH J (1983) Chromium and potassium accumulation influenced by body weight in goldfish (Carassius auratus). Bull. Environ. Contam. Toxicol. 30 331-336.

GALVIN RM (1996) Occurrence of metals in waters: an overview. Water SA 22 (1) 7-18.

GATLIN DM, PHILLIPS HF and TORRANS EL (1989) Effects of various levels of dietary copper and zinc on channel catfish. Aquaculture 76 127-134.

GBEM TT, BALOGUN JK, LAWAL FA and ANNUNE PA (2001) Trace metal accumulation in Clarias gariepinus (Teugels) exposed to sublethal levels of tannery effluent. Sci. Total. Environ. 271 1-9.

GROBLER E, DU PREEZ HH and VAN VUREN JHJ (1989) Toxic effects of zinc and iron on the routine oxygen consumption of Tilapia sparrmanii (Cichlidae). Comp. Biochem. Physiol. 94C (1) 207-214.

GROBLER-VAN HEERDEN E, VAN VUREN JHJ and DU PREEZ $\mathrm{HH}$ (1991) Bioconcentration of atrazine, zinc and iron in the blood of Tilapia sparrmanii (Cichlidae). Comp. Biochem. Physiol. 100C (3) 629-633.

HEIER LS, LIEN IB, STRØMSENG AE, LJØNES M, ROSSELAND BO, TOLLEFSEN K-E and SALBU B (2009) Speciation of lead, copper, zinc and antimony in water draining a shooting range Time dependant metal accumulation and biomarker responses in brown trout (Salmo trutta L.) Sci. Total. Environ. 407 4047-4055.

HOLDWAY DA (1988) The toxicity of chromium to fish. In: Nriagu JO and Nieboer E (eds.) Chromium in the Natural and Human Environments. Ch.15. John Wiley and Sons, New York.

HOPSON JL and WESSELS NK (1990) Essentials of Biology. McGraw Hill Publishing Company, New York.

HOUBA C, REMACLE J, DUBOIS D. and THOREZ J (1983) Factors affecting the concentrations of cadmium, zinc, copper and lead in the sediments of the Verde River. Water Res. 17 1281-1286.

JACKSON VA, PAULSE AN, VAN STORMBROEK T and KHAN W (2007) Investigation into metal contamination of the Berg River, Western Cape, South Africa. Water SA 33 (2) 175-182.

JACKSON VA, PAULSE AN, ODENDAAL JP and KHAN W (2009) Investigation into the metal contamination of the Plankenburg and Diep Rivers, Western Cape, South Africa. Water SA 35 (3) 289-300.

JAMES R, SAMPATH K and SELVAMANI P (1998) Effect of EDTA on reduction of copper toxicity in Oreochromis mossambicus (Peters). Bull. Environ. Contam. Toxicol. 60 487-493.

KAMAU JN (2002) Heavy metal distibution and enrichment at PortReitz Creek, Mombasa. West. Indian Ocean J. Mar. Sci. 1 (1) 65-70.

KARGIN F (1998) Metal concentrations in tissues of the freshwater fish Capoeta barroisi from the Seyhan River (Turkey). Bull. Environ. Contam. Toxicol. 60 822-828.

KIDWELL JM, PHILLIPS LJ and BIRCHARD GF (1995) Comparative analysis of contaminant levels in bottom feeding and predatory fish using the national contaminant biomonitoring program data. Bull. Environ. Contam. Toxicol. 54 919-923.

KIMBALL JW (1983) Biology. Addison-Wesley Publishing Company, Massachusetts.

KHANGAROT BS and RAY PK (1990) Acute toxicity and toxic interaction of chromium and nickel to common guppy Poecilia reticulata (Peters). Bull. Environ. Contam. Toxicol. 44 832-839.

KWONG RWM and NIYOGI S (2009) The interactions of iron with other divalent metals in the intestinal tract of a freshwater teleost, rainbow trout (Oncorhynchus mykiss). Comp. Biochem. Physiol. C 150 442-449.

LAKSHMANAN R, KESAVAN K, VIJAYANAND P, RAJARAM V and RAJAGOPAL S (2009) Heavy metals accumulation in five commercially important fishes of Parangipettai, Southeast Coast of India. Adv. J. Food Sci. Technol. 1 (1) 63-65.

LEWIS SD and LEWIS WM (1971) The effect of zinc and copper on the osmolality of blood serum of the channel catfish, Ictalurus punctatus Rafinesque, and golden shiner, Notemigonus crysoleucas Mitchill. Trans. Am. Fish. Soc. 4 639-643.

LLOYD R (1960) The toxicity of zinc sulphate to rainbow trout. Ann. Appl. Biol. 48 (1) 84-94. 
LLOYD R (1992) Pollution and Freshwater Fish. Fishing News Books, London.

MARTIN JLM (1974) Metals in Cancer irroratus (Crustacea: Decapoda): Concentrations, concentration factors, discrimination factors, correlations. Mar. Biol. 28 245-251.

MATHEWS T and FISHER NS (2009) Dominance of dietary intake of metals in marine elasmobranch and teleost fish. Sci. Total Environ. 407 5156-5161.

MENDIL D, ULUÖZLÜ ÖD, HASDEMIR E, TÜZEN M, SARI H and SUIÇMEZ M (2005) Determination of trace metal levels in seven fish species in lakes in Tokat, Turkey. Food Chem. 90 175-179.

MENDIL R, ÜNAL ÖF, TÜZEN M and SOYLAK M (2010) Determination of trace metals in different fish species and sediments from the River Yeşilırmak in Tokat, Turkey. Food Chem. Toxicol. 48 1383-1392.

MOHAN D, CHAUDHARY A and GAUR S (2008) Patterns of trace metals accumulation in different Trophic Levels of Lake Kailana, Jodhpur (India). Proc. Taal 2007: The $12^{\text {th }}$ World Lake Conf. 373-377.

MOODLEY KG, BAIJNATH H, SOUTHWAY-AJULU FA, MAHARAJ S and CHETTY SR (2007) Determination of Cr, $\mathrm{Pb}$ and $\mathrm{Ni}$ in water, sludge and plants from settling ponds of a sewage treatment works. Water $S A 33$ (5) 723-728

NATH K and KUMAR N (1987) Toxicity of manganese and its impact on some aspects of carbohydrate metabolism of a freshwater teleost, Colisa fasciatus. Sci. Total Environ. 67 257-262.

NEILANDS JB (1973) Chemistry of iron in biological systems. In: Dhar SK (ed.) Metal Ions in Biological Systems: Studies of some Biochemical and Environmental Problems. Plenum Press, New York. 13-42.

NESTO N, ROMANO S, MOSCHINO V, MAURI M and DA ROS L (2007) Bioacumulation and biomarker reponses of trace metals and micro-organic pollutants in mussels and fish from the Lagoon of Venice, Italy. Mar. Pollut. Bull. 55 469-484.

OTERO-MURAS I, FRANCO-URíA A, ALONSO AA and BALSACANTO E (2010) Dynamic multi-compartmental modelling of metal bioaccumulation in fish: Identifiability implications. Environ. Model. Softw. 25 344-353.

OYOO-OKOTH E, ADMIRAAL W, OSANO O, HOITINGA L and KRAAK MHS (2010) Metal specific partitioning in a parasite-host assemblage of the cestode Ligula intestinalis and the cyprinid fish Rastrineobola argentea. Sci. Total Environ. 408 1557-1562.

PALANIAPPAN PL RM and KARTHIKEYAN S (2009) Bioaccumulation and depuration of chromium in the selected organs and whole body tissues of freshwater fish Cirrhinus mrigala individually and in binary solutions with nickel. J. Environ. Sci. 21 229-236

PANDEY S, PARVEZ S, ANSARI RA, ALI M, KAUR M, HAYAT F, AHMAD F and RAISUDDIN S (2008) Effects of exposure to multiple trace metals in biochemical histological and ultrastructural features of gills of a freshwater fish, Channa punctata Bloch. Chem. Biol. Interact. 174 183-192.

PEREIRA P, DE PABLO H, VALE C and PACHECO M (2010a) Combined use of environmental data and biomarkers in fish (Liza aurata) inhabiting a eutrophic and metal-contaminated coastal system - gills reflect environmental contamination. Mar. Environ. Res. 69 53-62.

PEREIRA P, DE PABLO H, PACHECO M and VALE C (2010b) The relevance of temporal and organ specific factors in metals accumulation and biochemical effects in feral fish (Liza aurata) under a moderate contamination scenario. Ecotoxicol. Environ. Saf. 73 805-816.

PLAYLE RC (1998) Modelling metal interactions at fish gills. Sci. Total Environ. 219 147-163.

PRASATH PMD AND KHAN H (2008) Impact of Tsunami on the heavy metal accumulation in water, Sediments and fish at Poompuhar coast, Southeast Coast of India. E-Journal Chem. 5 (1) $16-22$

PYLE GG, RAJOTTE JW and COUTURE P (2005) Effects of industrial metals on wild fish populations along a metal contamination gradient. Ecotoxicol. Environ. Saf. 61 287-312.
QIAO-QIAO C, GUANG-WEI Z and LANGDON A (2007) Bioaccumulation of heavy metals in fishes from Taihu Lake, China. J. Environ. Sci. 19 1500-1504.

RAUF A, JAVED M and UBAIDULLAH M (2009) Heavy metal levels in three major carps (Catla catla, Labeo rohita and Cirrhina mrigala) from the river Ravi, Pakistan. Pakistan Vet. J. 29 (1) 24-26.

RETIEF N-R, AVENANT-OLDEWAGE A and DU PREEZ HH (2009) Seasonal study on Bothriocephalus as indicator of metal pollution in yellowfish, South Africa. Water SA 35 (5) 315-322.

REYNDERS H, BERVOETS L, GELDERS M, DE COEN WM and BLUST R (2008) Accumulation and effects of metals in caged carp and resident roach along a metal pollution gradient. Sci. Total Environ. 391 82-95.

ROBINSON J and AVENANT-OLDEWAGE A (1997) Chromium, copper, iron and manganese bioaccumulation in some organs and tissues of Oreochromis mossambicus from the lower Olifants River, inside the Kruger National Park. Water SA 23 (4) 387-403.

ROEBUCK BD (1992) Heavy metals. In: Smith RP (ed.) A Primer of Environmental Toxicology, Ch. 12. Lea \& Febiger, Philadelphia.

SCHMITT CJ, BRUMBAUGH WG and MAY TW (2007) Accumulation of metals in fish from lead-zinc mining areas of southeastern Missouri, USA. Ecotoxicol. Environ. Saf. 67 14-30.

SHAH SL and ALTINDAĞ A (2005) Effects of heavy metal accumulation on the 96-h $\mathrm{LC}_{50}$ values in tench Tinca tinca L., 1758. Turk. J. Vet. Anim. Sci. 29 139-144.

SHINN C, DAUBA F, GRENOUILLET G, GUENARD G and LEK $S$ (2009) Temporal variation of heavy metal contamination in fish of the river Lot in southern France. Ecotoxicol. Environ. Saf. 72 1957-1965

SKELTON P (2001) A Complete Guide to the Freshwater Fishes of Southern Africa. Struik Publishers, Cape Town.

SKIDMORE JF (1970) Respiration and osmoregulation in rainbow trout with gills damaged by zinc sulphate. J. Exp. Biol. 52 481-494. SORENSEN EM (1991) Metal Poisoning in Fish. CRC Press, Florida.

STRYDOM C, ROBINSON C, PRETORIUS E, WHITCUTT JM, MARX J and BORNMAN MS (2006) The effect of selected metals on the central metabolic pathways in biology: a review. Water $S A$ 32 (4) 543-554

SU GS, MARTILLANO KJ, ALCANTARA TP, RAGRAGIO E, DE JESUS J, HALLARE A and RAMOS G (2009) Assessing heavy metals in the waters, fish and macroinvertebrates in Manila Bay, Philippines. J. Appl. Sci. Environ. Sanit. 4 (3) 187-195.

TRAMA FB and BENOIT RJ (1960) Toxicity of hexavalent chromium to bluegills. J. WPCF 32 (8) 808-877.

UYSAL K, EMRE Y and KÖSE E (2008) The determination of heavy metal accumulation ratios in muscle, skin and gills of some migratory fish species by inductively coupled plasma-optical emission spectrometry (ICP-OES) in Beymelek Lagoon (Antalya/Turkey). Microchem. J. 90 67-70.

VAN AARDT WJ and ERDMANN R (2004) Heavy Metals (Cd, Pb, $\mathrm{Cu}, \mathrm{Zn})$ in mudfish and sediments from three hard-water dams of the Mooi River catchment, South Africa. Water SA 30 (2) 211-218.

VAN AARDT WJ and HOUGH M (2007) The effect of short-term $\mathrm{Cu}$ exposure on the oxygen consumption and $\mathrm{Cu}$ accumulation of mudfish (Labeo capensis) and the largemouth bass (Micropteris salmoides) in hard water. Water SA 33 (5) 701-708.

VINODHINI R and NARAYANAN M (2008) Bioaccumulation of heavy metals in organs of fresh water fish Cyprinus carpio (Common carp). Int. J. Environ. Sci. Tech. 5 (2) 179-182.

WELSH PG, PARROTT JL, DIXON DG, HODSON PV, SPRY DJ and MIERLE G (1996) Estimating acute copper toxicity to larval fathead minnow (Pimephales promelas) in soft water from measurements of dissolved organic carbon, calcium and pH. Can. J. Fish. Aquat. Sci. 53 1263-1271.

WOELFL S, MAGES M and TORRES P (2008) Trace metal concentrations in single specimens of the intestinal broad flatworm (Diphyllobothrium latum), compared to their fish host (Oncorhynchus mykiss) measured by total reflection X-ray fluorescence spectrometry. Spectrochim. Acta Part B 63 1450-1454.

WOODWARD DF, GOLDSTEIN JN, FARAG AM and BRUMBAUGH WG (1997) Cutthroat trout avoidance of metals and 
conditions characteristic of a mining waste site: Coeur d' Alene River, Idaho. Trans. Am. Fish Soc. 126 699-706.

YANG R, YAO T, XU B, JIANG G and XIN X (2007) Accumulation features of organochlorine pesticides and heavy metals in fish from high mountain lakes and Lhasa River in the Tibetan Plateau. Environ. Int. 33 151-156.
YILMAZ F, ÖZDEMIR N, DEMIRAK A and TUNA AL (2007) Heavy metal levels in two fish species Leuciscus cephalus and Lepomis gibbosus. Food Chem. 100 830-835.

YILMAZ AB, SANGÜN MK, YAĞLIOĞLU D and TURAN C (2010)

Metals (major, essential to non-essential) composition of the dif-

ferent tissues of three demersal fish species from İskenderun Bay, Turkey. Food Chem. 12341. 